Article

\title{
Environmentally Friendly Production of Methane from Natural Gas Hydrate Using Carbon Dioxide
}

\author{
Bjørn Kvamme
}

Strategic Carbon LLC, 20 Ladd St., Suite 200, Portsmouth, NH 03801, USA; bkvamme@strategic-carbonllc.com; Tel.: +1-47-934-51-956

Received: 7 March 2019; Accepted: 29 March 2019; Published: 2 April 2019

check for updates

\begin{abstract}
Huge amounts of natural gas hydrate are trapped in an ice-like structure (hydrate). Most of these hydrates have been formed from biogenic degradation of organic waste in the upper crust and are almost pure methane hydrates. With up to $14 \mathrm{~mol} \%$ methane, concentrated inside a water phase, this is an attractive energy source. Unlike conventional hydrocarbons, these hydrates are widely distributed around the world, and might in total amount to more than twice the energy in all known sources of conventional fossil fuels. A variety of methods for producing methane from hydrate-filled sediments have been proposed and developed through laboratory scale experiments, pilot scale experiments, and theoretical considerations. Thermal stimulation (steam, hot water) and pressure reduction has by far been the dominating technology platforms during the latest three decades. Thermal stimulation as the primary method is too expensive. There are many challenges related to pressure reduction as a method. Conditions of pressure can be changed to outside the hydrate stability zone, but dissociation energy still needs to be supplied. Pressure release will set up a temperature gradient and heat can be transferred from the surrounding formation, but it has never been proven that the capacity and transport ability will ever be enough to sustain a commercial production rate. On the contrary, some recent pilot tests have been terminated due to freezing down. Other problems include sand production and water production. A more novel approach of injecting $\mathrm{CO}_{2}$ into natural gas hydrate-filled sediments have also been investigated in various laboratories around the world with varying success. In this work, we focus on some frequent misunderstandings related to this concept. The only feasible mechanism for the use of $\mathrm{CO}_{2}$ goes though the formation of a new $\mathrm{CO}_{2}$ hydrate from free water in the pores and the incoming $\mathrm{CO}_{2}$. As demonstrated in this work, the nucleation of a $\mathrm{CO}_{2}$ hydrate film rapidly forms a mass transport barrier that slows down any further growth of the $\mathrm{CO}_{2}$ hydrate. Addition of small amounts of surfactants can break these hydrate films. We also demonstrate that the free energy of the $\mathrm{CO}_{2}$ hydrate is roughly $2 \mathrm{~kJ} / \mathrm{mol}$ lower than the free energy of the $\mathrm{CH}_{4}$ hydrate. In addition to heat release from the formation of the new $\mathrm{CO}_{2}$ hydrate, the increase in ion content of the remaining water will dissociate $\mathrm{CH}_{4}$ hydrate before the $\mathrm{CO}_{2}$ hydrate due to the difference in free energy.
\end{abstract}

Keywords: methane production; hydrate; carbon dioxide storage

\section{Introduction}

Industrial problems related to hydrate formation in pipelines and process equipment has historically motivated much of the hydrate research. In many of these systems, the heat released during hydrate formation is rapidly distributed through liquid water and solid metal. Related kinetic models have therefore typically focused on the thermodynamic driving force and related mass transport.

Classically, most hydrate risk evaluations have been based on the existence of a free liquid water phase, or the creation of a free water phase through condensation from water dissolved in gas (or liquid). The next step has typically been a consideration of how methanol, or other hydrate 
inhibitors, can shift the hydrate formation region; an example with methanol as inhibitor is illustrated in Figure 1 below. Experimental or theoretical curves like those presented in Figure $1 \mathrm{~b}$ have been utilized by the oil industry for several decades in order to decide how much methanol they should inject for specific situations of potential hydrate formation risk. Theoretical details and calculation procedures are discussed in Section 2. A typical example is given in Figure 2 below. A typical industrial risk evaluation approach is based on water condensing out as liquid (Figure 2a). During recent years, also the possibility of water dropping out from gas to adsorb on rusty pipeline walls has been investigated and typical calculations are presented in Figure $2 \mathrm{~b}$. Typically, the classical approach of calculating maximum water content before condensation will permit in the order of 20 times more water than a corresponding criteria based on water adsorption on rust.

During the latest few decades, the interest in natural gas hydrates as an energy source has increased substantially. Any method utilized to produce methane gas from methane gas hydrates will involve a transfer of heat. Most efforts have been on reducing the pressure to outside hydrate stability, which addresses the thermodynamic driving force, but the heat still needs to be supplied from the surroundings or added in some other way. Some very short pilot tests have been conducted in Alaska [1,2]. In more recent years, two tests were conducted offshore of Japan. The first one lasted for 6 days and was stopped due to problems with production of sand and water, as well as a freezing down due to limited heat supply capacity from the surroundings [3]. The second test was designed and planned for 6 months continuous production but closed down after 24 days due to freezing down problems [4]. Thermal stimulation, through for instance steam or hot water, is also possible but considered far too expensive as the only method. A more novel technology is to inject carbon dioxide. A solid-state mechanism has been proven by Ripmeester et al. [5] and Kuhs et al. [6] for the ice region of water. For temperatures above zero, a substantially faster mechanism $[7,8]$ involves the formation of a new $\mathrm{CO}_{2}$-dominated hydrate inside the pores using free water. Even in permafrost areas it is hard to find any natural gas hydrate deposits with higher hydrate saturations than $85 \%$ of the available pore volume. The more typical is $75 \%$ or lower like also in the Ignik Sikumi pilot test $[9,10]$. Injection of $\mathrm{CO}_{2}$ will lead to the formation of a new $\mathrm{CO}_{2}$ hydrate from the free water in the pores and the injected $\mathrm{CO}_{2}$. The use of pure $\mathrm{CO}_{2}$ will rapidly block the pores with $\mathrm{CO}_{2}$ hydrate films and slow down any exchange process with the in situ $\mathrm{CH}_{4}$ hydrate. In the Ignik Sikumi pilot test [9,10], a mixture of $77.5 \mathrm{vol} \% \mathrm{~N}_{2}$ and the rest $\mathrm{CO}_{2}$ was injected in order to limit and slow down the formation of a new $\mathrm{CO}_{2}$ dominated hydrate. Injecting very diluted $\mathrm{CO}_{2}$ mixtures in $\mathrm{N}_{2}$ will increase permeability for the injected gas but the damping of the new hydrate formation may be far too much for $\mathrm{CO}_{2}$ [10] to even be efficient as a mechanism for $\mathrm{CO}_{2} / \mathrm{CH}_{4}$ exchange in the pores. The addition of small amounts of surfactant will keep the interface free of hydrates [11] and stimulate hydrate nucleation and growth below the $\mathrm{CO}_{2} /$ water interface region. The effects of surfactant on interface free energy and increased solubility of $\mathrm{CO}_{2}$ below the surfactant stimulated interface are additional effects that will stimulate hydrate growth from solution. Practically it has been observed that small amounts of methanol will act as a promotor for hydrate formation in a pipeline [12].

A brief review of available experimental data for methane hydrate and carbon dioxide hydrate is given in Section 2. Claussius-Clapeyron and Clapeyron have been typical methods for estimating enthalpies of hydrate formation and these methods are briefly discussed in Section 3. In Section 4, we outline our approach based the use of residual thermodynamics for all components in all phases, including hydrate. Example calculations are presented in Section 5, followed by our conclusions. 


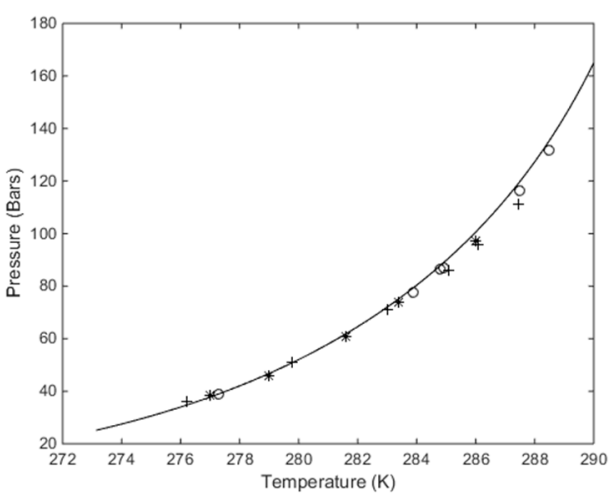

(a)

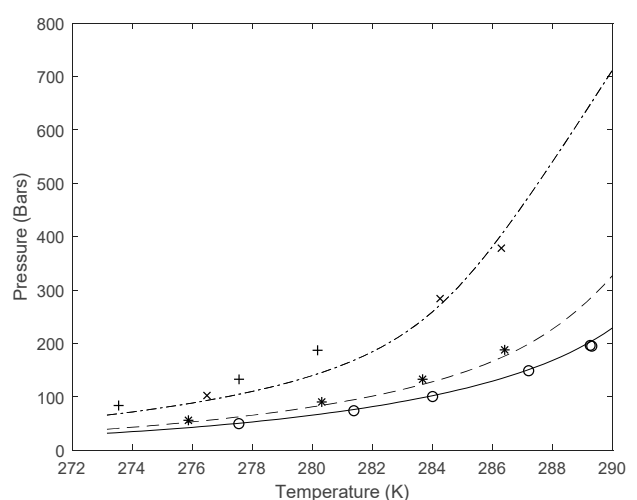

(b)

Figure 1. (a) Hydrate equilibrium curves for $\mathrm{CH}_{4}$ hydrate with temperature in kelvin and pressure in bar. The solid curve is calculated according to theory and procedures described in Section 2. * are experimental data from Bavoh et al. [13], + are experimental data from Tumba et al. [14] and o are experimental data from Sabil et al. [15]. (b) Hydrate equilibrium curves for hydrate formed from $\mathrm{CH}_{4}$ and water containing methanol. The solid curve is the calculated equilibrium curve for an amount of 5.44 weight per cent methanol in water. Circles are experimental data from Svartas and Fadnes [16]. The dashed curve is the calculated equilibrium curve for $10 \mathrm{wt} \%$ methanol in water and * are experimental data from $\mathrm{Ng}$ and Robinson [17]. The dash-dot curve is the calculated equilibrium curve for $20 \mathrm{wt} \%$ methanol in water and $\mathrm{x}$ are experimental data from $\mathrm{Ng} \&$ Robinson [17]. + are similar data from Svartås and Fadnes [16] but for $20.01 \mathrm{wt} \%$ methanol in water.

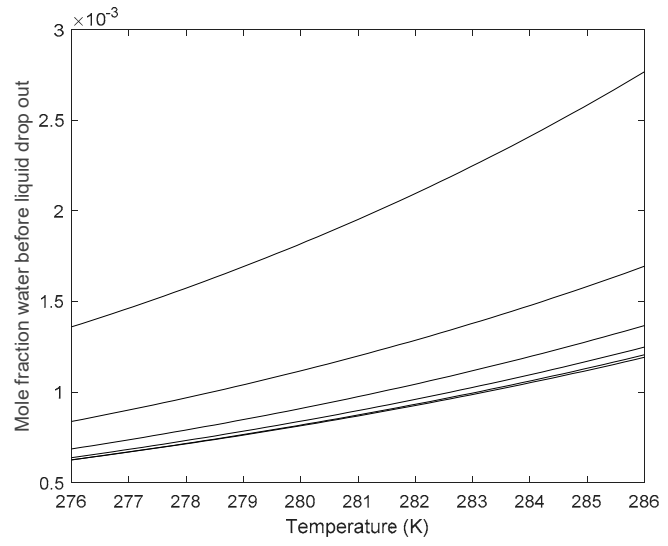

(a)

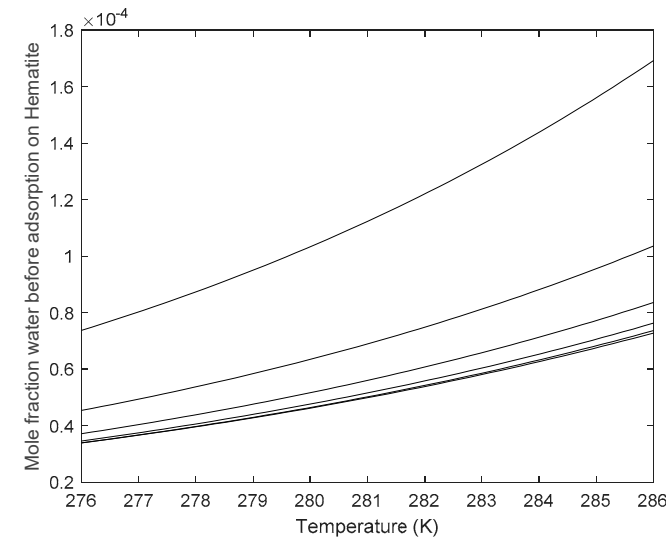

(b)

Figure 2. (a) Calculated maximum amounts of water in $\mathrm{CH}_{4}$ before condensing out as liquid water. (b) Maximum amounts of water in $\mathrm{CH}_{4}$ before adsorption on Hematite. For details on the theory and algorithms for these calculations, as well as other examples, the reader is directed to open literature. Some examples are given in References [10,18-28]. Highest curve is for 50 bars and lowest curve is for 270 bars in both graphs. Other pressures are evenly distributed with 44 bars increasing for each curve from the top 50 bars curves downwards.

\section{Residual Thermodynamic Modeling of Hydrate Formation from Water and a Separate Hydrate Former Phase}

By definition, a hydrate phase transition is reversible along the equilibrium curve. This is utilized for the Clapeyron-based methods for the formation of hydrate from a separate gas (or liquid) hydrate former phase and a free water phase. More specifically the Clapeyron method is based on the fact that $\mathrm{dG}=0$ for a phase equilibrium point of pressure and temperature. The application of this simple result to hydrate is not straightforward within the more typical ways to calculate hydrate equilibrium today. In view of Equation (3) below, the empty hydrate is frequently treated as an empirical fitting property. More precisely, the difference in chemical potential between pure liquid water and chemical potential 
in empty clathrate of structure I or II are treated as fitting parameters. Most often, this chemical potential difference at a reference state is fitted as one parameter. An associated enthalpy difference is also fitted, along with fitted differences for specific heat capacities and volume differences so as to be able to adjust chemical potential differences to the pressures and temperatures in consideration. The conditions for hydrate equilibrium are therefore, in this difference method, just a reformulation of Equation (2) below being equal to Equation (3). Empirical fitting of a fundamental property like chemical potential may not be the best way to treat hydrate, but there are also other challenges related to the Claussius approach for hydrate. This is, however, not an important focus in this work. A separate study is dedicated to a more critical review of that method, as well as simplified versions along the lines of Claussius-Clapeyron. These latter simplifications basically imply that condensed phase volumes are neglected. Claussius-Clapeyron models for hydrates are therefore typically only suitable for moderate pressures.

The free energy change for this phase transition can be written as:

$$
\Delta G^{\left(H_{1}\right)}=\left[\begin{array}{c}
x_{H_{2} O}^{H}\left(\mu_{H_{2} O}^{H}\left(T, P, \vec{x}^{H}\right)-\mu_{H_{2} O}^{\text {water }}(T, P, \vec{x})\right) \\
+\sum_{i} x_{i}^{H}\left(\mu_{i}^{H}\left(T, P, \vec{x}^{H}\right)-\mu_{i}^{\text {gas }}\left(T, P, \vec{y}^{\text {gas }}\right)\right)
\end{array}\right]
$$

The superscript $H_{1}$ is used to distinguish the specific heterogeneous phase transition from other hydrate formation phase transitions. $T$ is temperature and $P$ is pressure. $x$ is the mole-fraction in either liquid or hydrate (denoted with a subscript $H$ ), while $y$ is mole-fraction in the gas (or liquid) hydrate former phase. $i$ is an index for hydrate formers. The superscript water denotes the water phase that is converted into hydrate. Generally, this is ice or liquid, but in this work, we only consider liquid water. $\mu$ is the chemical potential.

The liquid water chemical potential is calculated from the symmetric excess conventions as:

$$
\mu_{\mathrm{H}_{2} \mathrm{O}}^{\text {water }}(T, P, \vec{x})=\mu_{\mathrm{H}_{2} \mathrm{O}}^{\text {pure, } \mathrm{H}_{2} \mathrm{O}}(T, P)+R T \ln \left[x_{\mathrm{H}_{2} \mathrm{O}} \gamma_{\mathrm{H}_{2} \mathrm{O}}(T, P, \vec{x})\right]
$$

where $\lim \left(\gamma_{\mathrm{H}_{2} \mathrm{O}}\right)=1.0$ when $x_{\mathrm{H}_{2} \mathrm{O}}$ approaches unity.

The chemical potential for water in the hydrate structure is given as [29]:

$$
\begin{gathered}
\mu_{\mathrm{H}_{2} \mathrm{O}}^{\mathrm{H}}=\mu_{\mathrm{H}_{2} \mathrm{O}}^{\mathrm{O} H}-\sum_{k=1,2} R T v_{k} \ln \left(1+\sum_{i} h_{i j}\right) \\
h_{k i}=e^{\beta\left[\mu_{k i}-\Delta g_{k i}\right]}
\end{gathered}
$$

where $\beta$ is the inverse of the universal gas constant times temperature. At equilibrium, the chemical potential of the guest molecules $i$ in hydrate cavity $k$ is equal to the chemical potential of molecules $i$ in the co-existing phase it comes from. For non-equilibrium, the chemical potential is adjusted for distance from equilibrium through a Taylor expansion as discussed later. The free energies of inclusion (latter term in the exponent) are reported elsewhere [10,18-29]. At thermodynamic equilibrium between a free hydrate former phase, $\mu_{k i}$ is the chemical potential of the guest molecule in the hydrate former phase (gas, liquid, or fluid) at the hydrate equilibrium temperature and pressure.

Hydrate equilibrium is then solved by fixing one of either temperature and pressure and using the fact that the chemical potential of water in hydrate (Equation (3)) and liquid water (Equation (2)) have to be equal. This is very similar to any other approach that utilizes a fugacity time Langmuir constant approach instead of Equation (4). As illustrated by Kvamme \& Tanaka [29] a version of Equation (4) for rigid water lattice is the best for small guest molecules. For $\mathrm{CH}_{4}$ the results from Equation (4), and from the more common integration over the Boltzmann factors for a rigid water lattice, the results are almost the same. $\mathrm{CO}_{2}$, on the other hand, is larger. Movements of $\mathrm{CO}_{2}$ in a large cavity of structure I interferes with water liberation movements and the impact is roughly a $1 \mathrm{~kJ} / \mathrm{mol}$ 
destabilization effect. However, the net effect of $\mathrm{CO}_{2}$ is still a substantially stronger attraction with water than $\mathrm{CH}_{4}$ in the same cavity type. The advantage of the formulation in Equation (4) is such that it can theoretically correct for large molecules that interfere with water lattice movements, and as such, alters the properties of the water. An example for methane is given in Figure 1a.

For the methanol addition, we have utilized the following model for water activity coefficients:

$$
\gamma_{\mathrm{H}_{2} \mathrm{O}}=a_{0}+a_{1} x_{\mathrm{H}_{2} \mathrm{O}}+a_{2} x_{\mathrm{H}_{2} \mathrm{O}}^{2}+a_{3} x_{\mathrm{H}_{2} \mathrm{O}}^{3}
$$

where each parameter takes the form (see Table 1 for values):

$$
a_{i}=a_{i, 1}+\frac{a_{i, 2}}{T_{R}}+\frac{a_{i, 3}}{T_{R}^{2}}
$$

Table 1. Parameters for Equation (6). Reduced temperature $T_{R}$ is $T / 273.15$.

\begin{tabular}{cccc}
\hline Parameters & $\boldsymbol{k}=\mathbf{1}$ & $\boldsymbol{k}=\mathbf{2}$ & $\boldsymbol{k}=\mathbf{3}$ \\
\hline$a_{0, k}$ & 0.748208 & 0.520769 & -0.599363 \\
$a_{1, k}$ & 0.541737 & -0.473879 & 0.547213 \\
$a_{2, k}$ & -0.538589 & 0.567666 & -0.525522 \\
$a_{3, k}$ & 0.350678 & -0.531175 & 0.373238 \\
\hline
\end{tabular}

Examples of the changes in chemical potential for water for various mole-fractions of methanol is illustrated in Figure 3a. Note that these values include all changes from pure liquid water, and as such, also contains the ideal missing term in the last term on right hand side of Equation (2). The effect on hydrate equilibrium is visible from the solutions of Equations (2) and (3). The same chemical potential for liquid water and hydrate water results in higher equilibrium pressures for increasing methanol mole-fractions. Some illustrations are given in Figure $1 \mathrm{~b}$ above. Equilibrium for $\mathrm{CH}_{4}$ is included through the same hydrate $\mathrm{CH}_{4}$ chemical potential in Equation (4) and in the separate $\mathrm{CH}_{4}$ gas phase. The change in hydrate-forming conditions, as well as the change in water enthalpy (see Figure 3b), also shifts the enthalpies of hydrate formation and dissociation.

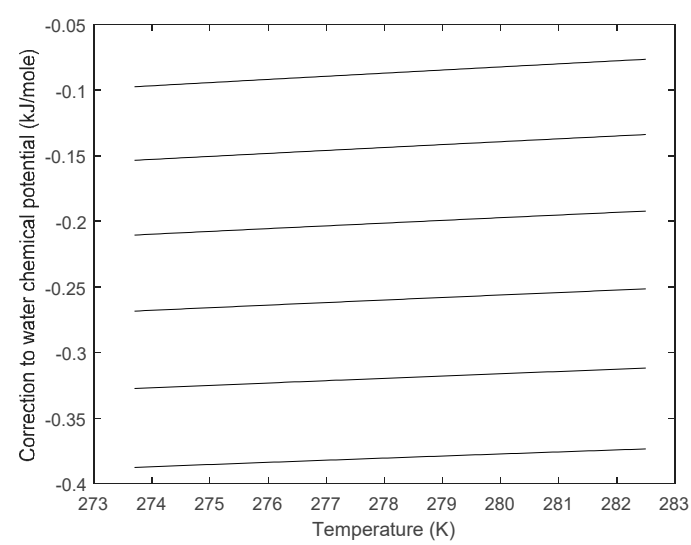

(a)

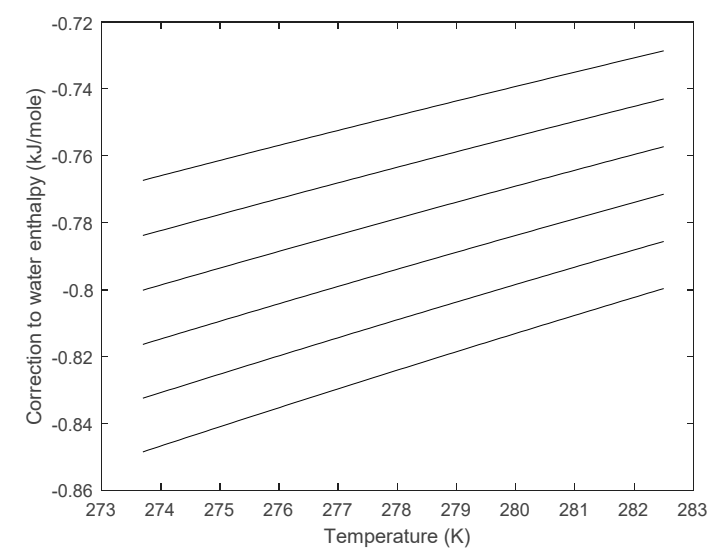

(b)

Figure 3. (a) Corrections to liquid water chemical potential as function of temperature, including the ideal mixing term. Upper curve is for $2 \mathrm{~mol} \%$ methanol, next is for $4 \mathrm{~mol} \%$ methanol, then $6 \mathrm{~mol} \%$ methanol, $8 \mathrm{~mol} \%$ methanol, $10 \mathrm{~mol} \%$ methanol, and finally $12 \mathrm{~mol} \%$ methanol for the lowest curve. (b) Corrections to liquid water enthalpy. Order of the curves from top to bottom is as explained in Figure 3a. 
The corresponding filling fractions and mole-fractions of methane in the hydrate is given by:

$$
\theta_{k i}=\frac{h_{k i}}{1+\sum_{j} h_{k i}}
$$

$\theta_{k i}$ is the filling fraction of component $i$ in cavity type $k$. Also:

$$
x_{i}^{H}=\frac{\theta_{\text {large }, i} v_{\text {large }}+\theta_{\text {small }, i} v_{\text {small }}}{1+\theta_{\text {large }, i} v_{\text {large }}+\theta_{\text {small }, i} v_{\text {small }}}
$$

where $v$ is the fraction of cavity per water for the actual cavity type, as indicated by subscripts. The corresponding mole-fraction water is then given by:

$$
x_{\mathrm{H}_{2} \mathrm{O}}^{\mathrm{H}}=1-\sum_{i} x_{i}^{H}
$$

and the associated hydrate free energy is then:

$$
G^{(H)}=x_{H_{2} \mathrm{O}}^{H} \mu_{H_{2} \mathrm{O}}^{H}+\sum_{i} x_{i}^{H} \mu_{i}^{H}
$$

in which $\mu$ denotes the chemical potential. Subscripts $\mathrm{H}_{2} \mathrm{O}$ and $i$ denote water and hydrate formers, respectively. Superscripts $H$, water, and gas denote hydrate, liquid water, and gas phases, respectively. $x$ is the mole-fraction in liquid or hydrate (superscript $H$ ) and $y$ is the mole-fraction in hydrate former phase. $T$ and $P$ are temperature and pressure, respectively, and $G$ is the free energy. The $\Delta$ symbol, the change in free energy, and superscript $H_{1}$ indicate this hydrate formation route.

The chemical potential for guest molecule $\mathrm{j}$ (in the case of this work either $\mathrm{CO}_{2}$ or $\mathrm{CH}_{4}$ ), which enters Equations (4) and (8) at equilibrium is, according to residual thermodynamics:

$$
\mu_{i}(T, P, \vec{y})=\mu_{i}^{\text {pure, idealgas }}(T, P, \vec{y})+R T \ln \left[y_{i} \phi_{i}(T, P, \vec{y})\right]
$$

where $y_{i}$ is mole-fraction of component $i$ in the gas mixture. $\phi_{i}$ is the fugacity coefficient for $i$. Ideal gas chemical potential for pure $i$ can be trivially calculated for any model molecule via statistical mechanics from mass and intramolecular structure (bond lengths and bond angles). Together with density and temperature, the ideal gas chemical potential is available from the momentum space canonical partition function. We have utilized the SRK [30] equation of state for calculating the fugacity coefficient and the density needed for the ideal gas free energy calculations.

Calculated hydrate equilibrium curves for $\mathrm{CH}_{4}$ and $\mathrm{CO}_{2}$ are plotted in Figure 4a. $\mathrm{CH}_{4}$ is supercritical and the corresponding hydrate equilibrium curve is smooth. $\mathrm{CO}_{2}$, on the other hand, goes through a phase transition that changes the density of $\mathrm{CO}_{2}$. This changes the fugacity coefficient for $\mathrm{CO}_{2}$ substantially (see Equation (11)) and results in a steep change in $\mathrm{CO}_{2}$ hydrate equilibrium pressures over the narrow temperature range for the phase transition. It is beyond the scope of this work to discuss the rapid change in the $\mathrm{CO}_{2}$ hydrate equilibrium curve. However, there are some frequent misunderstandings in the open literature on experimental data for $\mathrm{CO}_{2}$ hydrate; see, for instance, Reference [20] for some examples and associated discussion. 


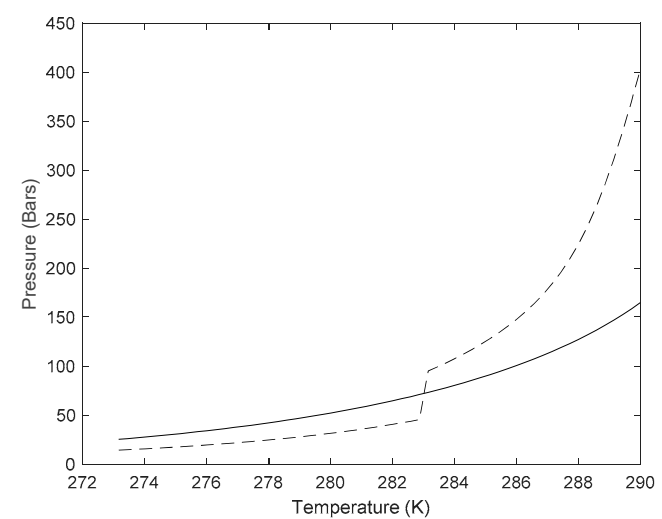

(a)

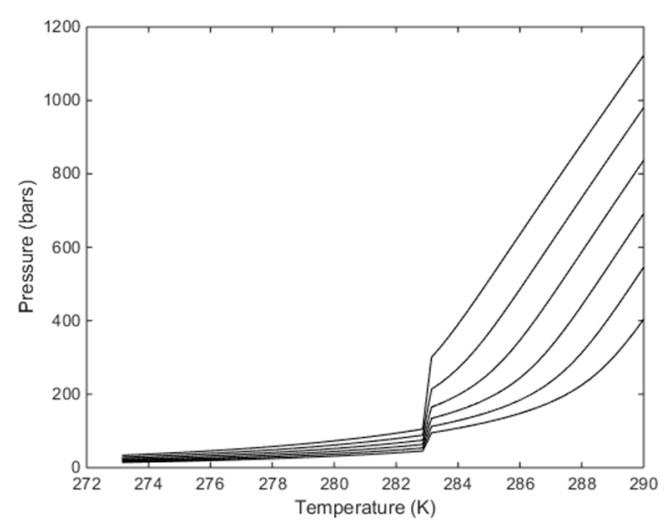

(b)

Figure 4. (a) Hydrate equilibrium curves for $\mathrm{CH}_{4}$ hydrate (solid) and $\mathrm{CO}_{2}$ hydrate (dashed). (b) Calculated hydrate equilibrium curves for various amounts of methanol in water. Pressure is in bar. Lowest curve is for pure water and upper curve is for $12 \mathrm{~mol} \%$ methanol. Curves in between are (from second curve and up) 2, 4, 6, 8, and $10 \mathrm{~mol} \%$ methanol.

As mentioned before, it is not actually the pressure-temperature projection that is important for the replacement of in situ $\mathrm{CH}_{4}$ hydrate with $\mathrm{CO}_{2}$. It is the free energy differences of the two hydrates and the heat of formation of $\mathrm{CO}_{2}$ hydrate relative to the heat of formation for the $\mathrm{CH}_{4}$ hydrate. Free energy of the $\mathrm{CH}_{4}$ hydrate along the equilibrium curve plotted in Figure 1a is illustrated in Figure 5a. Corresponding results for $\mathrm{CO}_{2}$ hydrate along the equilibrium curve in Figure $1 \mathrm{~b}$ is plotted in Figure $5 \mathrm{~b}$. $\mathrm{CO}_{2}$ hydrate is thermodynamically more stable than $\mathrm{CH}_{4}$ hydrate in terms of free energy for the range of temperatures from $273.15 \mathrm{~K}$ to $290 \mathrm{~K}$.

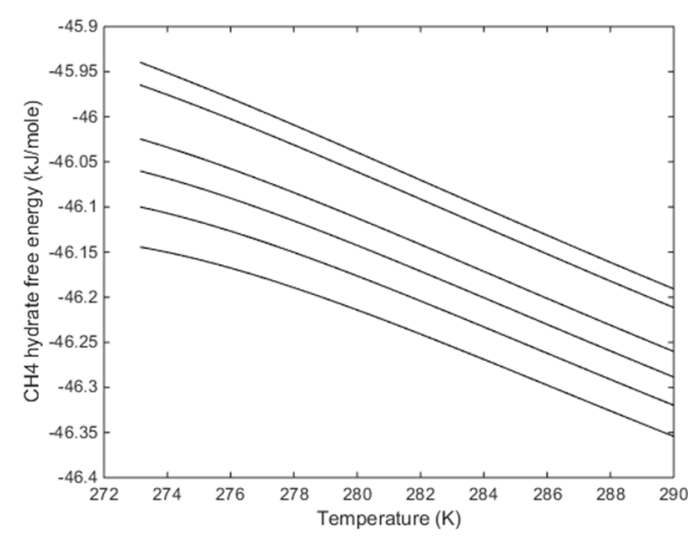

(a)

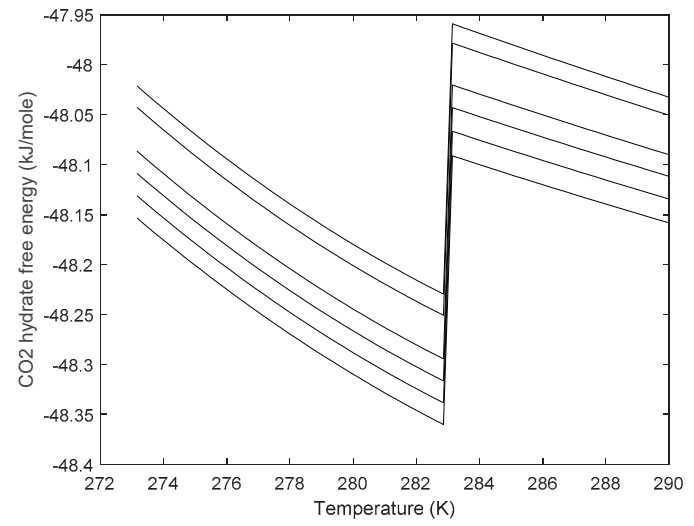

(b)

Figure 5. (a) Free energy of $\mathrm{CH}_{4}$ hydrate along the equilibrium curves for various concentrations of methanol in water. From lowest curves and up: 0, 2, 4, 6, 8, 10, and $12 \mathrm{~mol} \%$ for upper curve. (b) Free energy of $\mathrm{CO}_{2}$ hydrate along the equilibrium curve. From lowest curves and up: 0,2, 4, 6, 8, 10, and $12 \mathrm{~mol} \%$ for upper curve.

The enthalpy change is trivially related to the corresponding free energy change uisng the thermodynamic relationship:

$$
\frac{\partial\left[\frac{\Delta G^{\text {Total }}}{R T}\right]_{P, \vec{N}}}{\partial T}=-\left[\frac{\Delta H^{\text {Total }}}{R T^{2}}\right]
$$

The superscript total is introduced to also include the penalty of pushing aside the old phases. Practically, the total free energy change will be Equation (1) plus the interface free energy times the 
contact area between the water and hydrate forming phase during the nucleation stage divided by number of molecules in the specific core size. Since critical nuclei sizes are small [23-25], the whole particle can be considered as covered with water due to capillary forces. Above the critical core size, the penalty diminishes rapidly relative to the free energy benefits from Equation (1).

$$
\frac{\partial\left[\frac{\mu_{H_{2} O}^{H}}{R T}\right]_{P, \vec{N}}}{\partial T}=\frac{\partial\left[\frac{\mu_{H_{2} O}^{0, H}}{R T}\right]_{P, \vec{N}}}{\partial T}-\left[\frac{\partial}{\partial T}\right]_{P, N}\left[\sum_{k=1,2} v_{k} \ln \left(1+\sum_{i} h_{k i}\right)\right]
$$

For the liquid water phase in Equation (1), as well as for the empty hydrate chemical potential on the right hand side of Equation (3), results are trivially obtained from Kvamme and Tanaka [29], while the second term on the right hand side is reorganized as:

$$
\left[\frac{\partial}{\partial T}\right]_{P, \vec{N}}\left[\sum_{k=1,2} v_{k} \ln \left(1+\sum_{i} h_{k i}\right)\right]=\left[\sum_{k=1,2} v_{k} \frac{\sum_{i}\left[\frac{\partial h_{k i}}{\partial T}\right]_{P \vec{N}}}{\left(1+\sum_{i} h_{k i}\right)}\right]
$$

Furthermore, the derivatives of the cavity partition functions can be written as:

$$
\left[\frac{\partial h_{k i}}{\partial T}\right]_{P \vec{N}}=h_{k i}\left[-\frac{1}{R T^{2}}\left(\mu_{k i}-\Delta g_{k i}\right)+\frac{1}{R T}\left(\frac{\partial \mu_{k i}}{\partial T}-\frac{\partial \Delta g_{k i}}{\partial T}\right)\right]
$$

The partial derivatives in the last term on right hand side is numerically differentiated from the polynomial fits of Kvamme and Tanaka [29]:

$$
\begin{gathered}
\frac{\partial\left[\frac{\mu_{\mathrm{H}_{2} \mathrm{O}}^{\mathrm{H}}}{R T}\right]_{P, \vec{N}}}{\partial T}=\frac{\partial\left[\frac{\mu_{\mathrm{H}_{2} \mathrm{O}}^{0, H}}{R T}\right]_{P, \vec{N}}}{\partial T}+\left[\sum_{k=1,2} v_{k} \frac{\sum_{i} h_{k i}\left[\frac{1}{R T^{2}}\left(\mu_{k i}-\Delta g_{k i}\right)-\frac{1}{R T}\left(\frac{\partial \mu_{k i}}{\partial T}-\frac{\partial \Delta g_{k i}}{\partial T}\right)\right]}{\left(1+\sum_{i} h_{k i}\right)}\right] \\
H_{H_{2} \mathrm{O}}^{H}=-R T^{2} \frac{\partial\left[\frac{\mu_{H_{2} O}^{0, H}}{R T}\right]_{P, \vec{N}}}{\partial T}+\left[\sum_{k=1,2} v_{k} \frac{\sum_{i} h_{k i}\left[\left(\mu_{k i}-\Delta g_{k i}\right)-T\left(\frac{\partial \mu_{k i}}{\partial T}-\frac{\partial \Delta g_{k i}}{\partial T}\right)\right]}{\left(1+\sum_{i} h_{k i}\right)}\right]
\end{gathered}
$$

The final term on the right-hand side is also sampled from molecular simulation (MD) sampling along with the free energies of inclusion. The largest distinction in that term is between methane in large and small cavity. For temperatures between 273.15 and $290 \mathrm{~K}$, these are almost straight lines, but a second-order fit of the MD sampled result to the following second order polynomial:

$$
\frac{\partial \Delta g_{k i}}{\partial T}=a_{0}+a_{1} T_{R}+a_{2} T_{R}^{2}
$$

Equation (18) gives a good fit to the sampled data. Subscript $R$ on $T$ on the right-hand side of Equation (18) indicate the reduced temperature. This is defined as $T$ divided by critical temperature for the components in consideration. Parameters are given in Table 2 below. 
Table 2. Parameters for Equation (16). Small cavity in structure I are not stabilized for the actual temperature range and $h_{k i}=0$ for $\mathrm{CO}_{2}$ in small cavities. The critical temperature for $\mathrm{CH}_{4}$ is $190.55 \mathrm{~K}$ and critical temperature for $\mathrm{CO}_{2}$ is $304.25 \mathrm{~K}$.

\begin{tabular}{ccccc}
\hline Comp. $\boldsymbol{i}$ & Cavity $\boldsymbol{k}$ & $\boldsymbol{a}_{\mathbf{0}}$ & $\boldsymbol{a}_{\mathbf{1}}$ & $\boldsymbol{a}_{\mathbf{2}}$ \\
\hline \multirow{2}{*}{$\mathrm{CH}_{4}$} & Large & -0.458007 & 0.266046 & 0 \\
& Small & 0.689560 & -0.796062 & 0.234249 \\
\hline $\mathrm{CO}_{2}$ & Large & -0.652590 & 0.649258 & 0 \\
\hline
\end{tabular}

For liquid water, the enthalpy is even more trivially obtained using numerical differentiation of the polynomial fit of chemical potential as a function of $T$ given by Kvamme and Tanaka [29].

In an equilibrium situation, the chemical potential of the same guest in the two cavity types must be the same. Furthermore, these guest chemical potentials must be equal to the chemical potential of the same molecule in the phase that it came from (gas, dissolved in water, adsorbed on mineral surface). For the heterogeneous case, this means the chemical potential of the molecule in gas (or liquid) hydrate former phase. However, outside of equilibrium, the gradients in chemical potentials as a function of $T$, $P$, and mole-fractions have to reflect how the molecule behaves in the cavity.

Enthalpies for various guest molecules in the two types of cavities can be evaluated using Monte Carlo simulations along the lines described by Kvamme and Lund [31] and Kvamme and Førrisdahl [32] by sampling guest water interaction energies and efficient volumes from the movements of the guest molecules. The final result needed here:

$$
H_{k i}^{R}=U_{k i}^{R}+\left(z_{k i}-1\right) R T
$$

where $U$ is energy and superscript $R$ denotes the residual (interaction) contribution. $z_{k i}$ is the compressibility factor for the guest molecule $i$ in cavity $k$. Calculations of consistent ideal gas values for the same interaction models that were used in calculation of the residual values is trivial:

$$
z_{k i}=\frac{P V_{k i}}{k_{B} T}
$$

in which $k_{B}$ is Boltzmann's constant and $V_{k i}$ is the excluded volume of a molecule of type $i$ in cavity of type $k$. This latter volume is calculated from the sampled volume of the center of mass movements plus the excluded volume due to water/guest occupation. The sampled values for residual energies and occupation volumes for the various cavities are given in Table 3 below. Slightly more complex sampling and calculation for molecules that are not monoatomic (or approximated as monoatomic like methane) but still fairly standard [31,32] and explicit discussion on this is not needed here.

For a relevant temperature span in the order of $10 \mathrm{~K}(273-283 \mathrm{~K})$, the differences in residual energies from Monte Carlo sampled data does not vary substantially, and that is why they are listed as constant values for the indicated temperature span. The same values are also used up to $290 \mathrm{~K}$. This is as expected since the hydrate water lattice is fairly rigid and the average movements are almost the same for the limited temperature range. The sampled cavity partition functions will of course vary significantly over the same temperature range due to the direct exponential (Boltzmann factor) dependency. The interaction models for $\mathrm{CH}_{4}$ and $\mathrm{CO}_{2}$ utilized are the same as those utilized by Kvamme and Tanaka [29]. An average attraction is also indicated for $\mathrm{CO}_{2}$ in small cavities. However, the sampled Langmuir constant is very small and not significant. This is also confirmed by the molecular dynamics studies along the lines of Kvamme \& Tanaka [29] for which the movements of $\mathrm{CO}_{2}$ in the small cavity interferes with several water libration frequencies. The resulting free energy of inclusion is not beneficial for $\mathrm{CO}_{2}$ in the small cavity. Small cavity occupation of $\mathrm{CO}_{2}$ has been found at extreme conditions in the ice range of temperatures in some studies [29]. However, it remains unclear and unverified whether there would be any significant filling of $\mathrm{CO}_{2}$ in small cavities for temperatures above zero degrees Celsius. 
Table 3. Sample residual energies, $U^{R}$, and cavity occupation volumes for $\mathrm{CH}_{4}$ and $\mathrm{CO}_{2}$.

\begin{tabular}{ccccc}
\hline Property & \multicolumn{2}{c}{$\mathrm{CH}_{\mathbf{4}}$} & \multicolumn{2}{c}{$\mathrm{CO}_{\mathbf{2}}$} \\
\hline & Large Cavity & Small Cavity & Large Cavity & Small Cavity \\
\hline$U_{k i}^{R}(\mathrm{~kJ} /$ mole $)$ & -16.53 & -17.73 & -27.65 & -10.58 \\
$V_{k i}\left(\AA^{3}\right)$ & 164.2 & 89.2 & 135.6 & 76.9 \\
\hline
\end{tabular}

The energies for $\mathrm{CO}_{2}$ in small cavities was sampled after a structure I containing only $\mathrm{CO}_{2}$ in large cavities was stabilized. Then, small cavities were gradually filled and simulations were run until the average fluctuations in the sampled interaction energies were symmetrical and on average less than $0.5 \%$ of the average energy for the hydrate crystal. Practically, this energy value does not have any implication on the enthalpy since the canonical partition function for $\mathrm{CO}_{2}$ in small cavity is practically zero, and as such also the filling fraction of $\mathrm{CO}_{2}$ in small cavity is almost zero. At pressures below 95 bars along the equilibrium curve, it is zero to the third digit in mole-fraction, while the maximum filling fraction in small cavity contributes with 0.006 to the mole-fraction at $(290.00 \mathrm{~K}, 403.0$ bars). In contrast, the calculated mole-fractions of methane in structure I varied between 0.134 at $(276.16 \mathrm{~K}$, 25.2 bars) along the equilibrium curve to 0.138 at ( $290.00 \mathrm{~K}, 164.7$ bars).

The derivative of the chemical potential of a guest molecule $\mathrm{i}$ in cavity type $\mathrm{k}$ with respect to temperature, as needed in Equation (15), is the negative of partial molar entropy for the same guest molecule and can be calculated according to:

$$
\left[\frac{\partial \mu_{k i}}{\partial T}\right]_{P \vec{N}}=\frac{\mu_{k i}-H_{k i}}{T}
$$

Equation (15) can then be rearranged into:

$$
H_{H_{2} \mathrm{O}}^{\mathrm{H}}=-R T^{2} \frac{\partial\left[\frac{\mu_{\mathrm{H}_{2} \mathrm{O}}^{0, H}}{R T}\right]_{P, \mathrm{~N}}}{\partial T}+\left[\sum_{k=1,2} v_{k} \frac{\sum_{i} h_{k i}\left[\left(H_{k i}-\Delta g_{k i}+T \frac{\partial \Delta g_{k i}}{\partial T}\right)\right]}{\left(1+\sum_{i} h_{k i}\right)}\right]
$$

The sampled temperature derivatives of guest inclusion free energies for methane in small cavity exhibits very different behavior due to the slightly higher density (roughly $85 \%$ higher density as compared to $\mathrm{CH}_{4}$ in large cavities). $\mathrm{CO}_{2}$ in small cavities is not relevant since the canonical partition functions are practically zero within significance.

Residual enthalpies for a hydrate former in a separate hydrate former phase are trivially given using:

$$
H_{i}^{R}=-R T^{2} \sum_{i} y_{i}\left[\frac{\partial \ln \phi_{i}^{g a s}}{\partial T}\right]_{P, y_{j \neq i}}
$$

in which the same equation of state (SRK) is utilized as the one used for calculating fugacity coefficients for the chemical potentials. As examples, we plot the calculated equilibrium curves for $\mathrm{CH}_{4}$ and $\mathrm{CO}_{2}$ in Figure $2 \mathrm{a}$ and the corresponding calculated heats of hydrate formation along the equilibrium curves in Figure 2b. The calculated results for $\mathrm{CH}_{4}$ in Figure $1 \mathrm{a}$ is compared to experimental data in Kvamme et al. [11], and comparison between calculated results and experimental data for the $\mathrm{CO}_{2}$ equilibrium curve can be found in Kvamme [10].

Experimental data on enthalpies of hydrate formation (or dissociation) are frequently missing various pieces of information that is important for quantitative comparison. The hydrate number is often missing or set to a fixed (guessed) number. Pressure is sometimes missing and temperature is not always given. Therefore, the degree of superheating relative to the hydrate stability limit is not always available. It is beyond the scope of this work to conduct a detailed review of the various data we have 
used for comparison. Readers are directed to the original sources listed in the caption to Figure 6. Work is in progress on a more detailed review of experimental data for the heats of dissociation of hydrates.

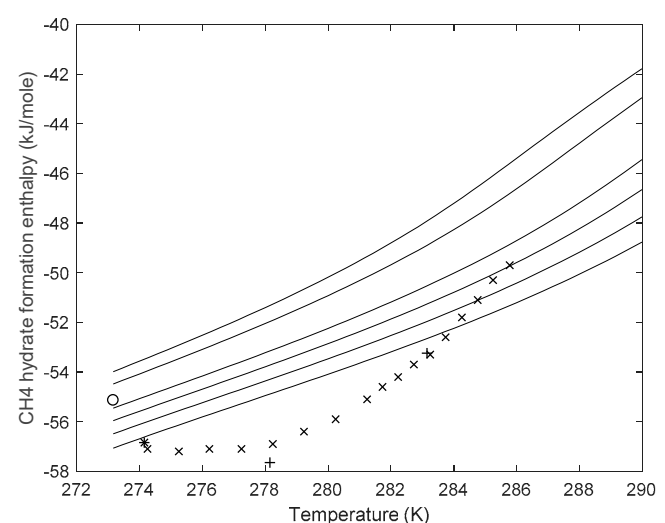

(a)

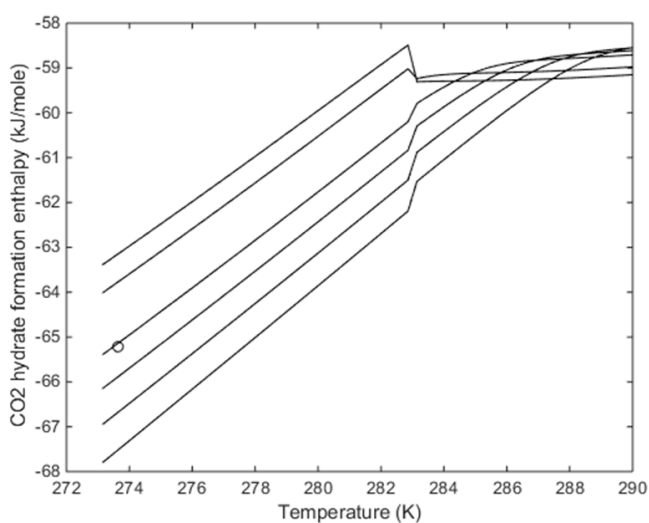

(b)

Figure 6. (a) Estimated heats of formation based residual thermodynamics for $\mathrm{CH}_{4}$ (solid) as a function of methanol mole-fraction in water. Lowest curve is for pure water and highest curve is for $12 \mathrm{~mol} \%$ methanol. Second curve from bottom is for $2 \mathrm{~mol} \%$ methanol, then $4 \mathrm{~mol} \%$ methanol, $6 \mathrm{~mol} \%$ methanol, $8 \mathrm{~mol} \%$ methanol, and $10 \mathrm{~mol} \%$ methanol. Some results from open sources for pure water are also plotted: data from Nakamura et al. [31] (x), Deaton and Frost [32] $\left(^{*}\right)$, Kang [33] (o), and Lievois [34] $(+)$. (b) Estimated heats of formation based residual thermodynamics for $\mathrm{CO}_{2}$ (solid). Same notations as in Figure $6 \mathrm{a}$ as a function of $\mathrm{mol} \%$ methanol in water. One available value from Kang [33] for pure water is also plotted using 0 .

Outside of equilibrium, the only phase that needs special attention is the hydrate phase since description of all fluids phase are continuous while the theory for hydrates is based on a Langmuir type of equilibrium adsorption theory:

$$
G_{\text {Non-equilibrium }}^{H}(T, P, \vec{x})=\left[\begin{array}{c}
\left.G^{H, \mathrm{Eq} \cdot\left(T^{\mathrm{Eq}}, P^{\mathrm{Eq} \cdot,}, \vec{x}\right.}{ }^{\mathrm{Eq} \cdot}\right)+\left.\sum_{r} \frac{\partial G^{H}}{\partial x_{r}}\right|_{P, T, x_{i \neq r}}\left(x_{r}-x_{r}^{\mathrm{Eq} \cdot}\right) \\
+\left.\frac{\partial G^{H}}{\partial P}\right|_{T, \vec{x}}\left(P-P^{\mathrm{Eq} \cdot}\right)+\left.\frac{\partial G^{H}}{\partial T}\right|_{P, \vec{x}}\left(T-T^{\mathrm{Eq} \cdot}\right)
\end{array}\right]
$$

in which the equilibrium properties, as a reference state, is available from the calculations leading to Figure 1a. The third term on the right-hand side is a trivial volume term and the final temperature term on the right-hand side can be avoided by expanding in a constant temperature from the equilibrium curve. The second term involves an iteration in which a new set of filling fractions are calculated from the properties at the new pressure. The correction is very limited and no further iteration is needed. The corresponding chemical potentials needed for Equation (8) in the non-equilibrium situation is then trivially given using:

$$
\mu_{m}^{H}(T, P, \vec{x})=\left[\frac{\partial\left(N G_{\text {Non-equilibrium }}^{H}(T, P, \vec{x})\right)}{\partial N_{m}}\right]_{T, P, N_{k \neq m}}
$$

This then, in turn, can be used for the calculation of the phase transition enthalpies outside of hydrate equilibrium.

As discussed by Kvamme et al. [11], small amounts of methanol will concentrate on the interface between liquid water and a non-polar (or slightly polar) hydrate former phase. This will keep the interface free of hydrate. Heterogeneous hydrate nucleation is therefore only examined for methanol 
concentrations up to $2 \mathrm{~mol} \%$. For this purpose, we utilize the classical nucleation theory (CNT) because it is simple enough to also be implemented in industrial tools, as well as in reservoir modelling.

The primary reason for conducting these calculations is that we want to illustrate the common misunderstanding that $\mathrm{CO}_{2}$ injection is not a feasible way to produce hydrate because it is slow. As discussed by Kvamme et al. [11], $\mathrm{CH}_{4}$ hydrate nucleation is very fast and a nanoscale process in time and volume. In terms of physics, this is not surprising, and it falls well into nucleation times for ice and other phases of complexity similar to hydrates. Since CNT is described in more detail in many other places, including our paper on $\mathrm{CH}_{4}$ hydrate nucleation [11], only a very brief presentation is given here so as to explain symbols.

Kinetic models for hydrates are implicit in terms of mass transport, heat transport, and thermodynamic control of the phase transition. This is true even for the simplest theory of all of the classical theory (CNT).

The mass transport fluxes need various kinetic theories, e.g., Multicomponent Diffuse Interface Theory (MDIT) theory [33-35], which reduces to the classical theory for a multi-component system when the interface thickness in MDIT theory goes to zero. For an illustration of the coupled transport and thermodynamic control of the phase transition kinetics, CNT serves as an easy method here because of the separation of contributions:

$$
J=J_{0} e^{-\beta \Delta G^{\text {Total }}}
$$

where $J_{0}$ is the mass transport flux supplying the hydrate growth. For the phase transition in Equation (1), it will be the supply of $\mathrm{CO}_{2}$ across an interface of gradually more structured water towards the hydrate core, as discussed in Kvamme et al. [11]. In Equation (10), it will be the diffusion rate for dissolved $\mathrm{CO}_{2}$ to crystal growth from aqueous solution. The units of $J_{0}$ will be $\mathrm{mol} / \mathrm{m}^{2} \mathrm{~s}$ for heterogeneous hydrate formation on the growing surface area of the hydrate crystal. $\beta$ is the inverse of the gas constant times temperature and $\Delta G^{\text {Total }}$ is the molar free energy change of the phase transition. This molar free energy consists of two contributions: (1) the phase transition free energy as described by Equation (1), and (2) the penalty work of pushing aside old phases. Since the molar densities of liquid water and hydrate are reasonably close, it is a fair approximation to multiply the molar free energy of the phase transition with molar density of hydrate times the volume of the hydrate core. The push-work penalty term is simply the interface free energy times the surface area of the hydrate crystal. Using lines below symbols to indicate extensive properties (unit: J):

$$
\Delta \underline{G}^{\text {Total }}=\Delta \underline{G}^{\text {Phasetransition }}+\Delta \underline{G}^{\text {Pushwork }}
$$

For the simplest possible geometry of a crystal, which is a sphere with radius $R$, we then get:

$$
\Delta \underline{G}^{\text {Total }}=\frac{4}{3} \pi R^{3} \rho_{N}^{H} \Delta G^{\text {Phasetransition }}+4 \pi R^{2} \gamma
$$

where $\rho_{N}^{H}$ is the molar density of the hydrate and $\gamma$ is the interface free energy between the hydrate and surrounding phase. Even if a hydrate core that grows on the surface of water is floating, it is expected that small crystals are likely to also be covered by water towards the gas side due to capillary forces that will facilitate transport and adsorption of water molecules from the liquid water side to also cover the hydrate particle on the gas side.

Differentiation of Equation (25) with respect to R and solving for the maximum free energy radius (the critical core size) gives the usual result:

$$
R^{*}=-\frac{2 \gamma}{\rho_{N}^{H} \Delta G^{\text {Phasetransition }}}
$$


in which the superscript ${ }^{*}$ denotes the critical nuclei radius. Critical radius for three different temperatures and four concentrations of methanol in water is given in Figure 7 below. For the two temperatures below the transition over to high density $\mathrm{CO}_{2}$, the trend is very similar to what was observed from phase field theory (PFT) modelling [27,36]. The exception is for hydrate forming from liquid $\mathrm{CO}_{2}$ as seen from the dash-dot curves in Figure 7 by the large critical radii, even for pure liquid water.

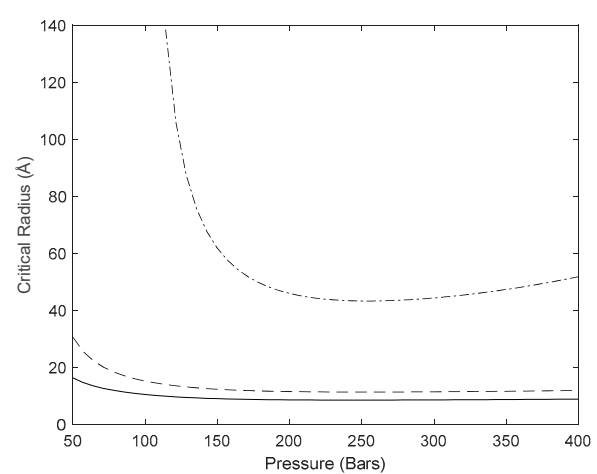

(a)

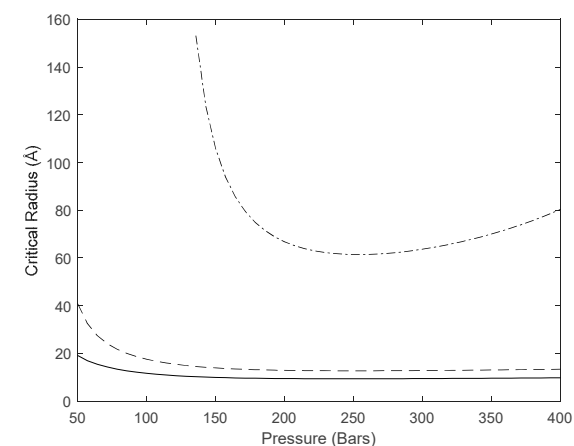

(c)

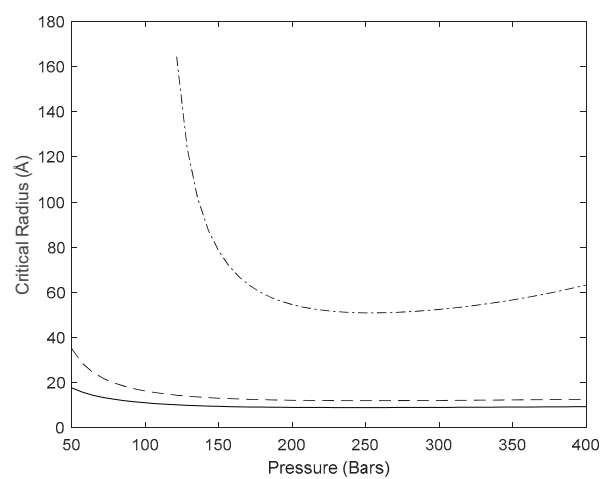

(b)

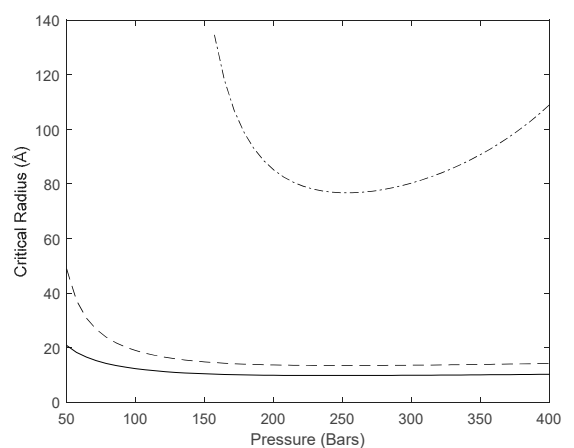

(d)

Figure 7. (a) Calculated critical radius for pure water and three different temperatures: $273.16 \mathrm{~K}$ (solid), $278.16 \mathrm{~K}$ (dash), and $283.16 \mathrm{~K}$ (dash-dot). (b) Same as (a) but now for $1 \mathrm{~mol} \%$ methanol in water. (c) Same as (a) but now for $2 \mathrm{~mol} \%$ methanol in water. (d) Same as (a) but for $3 \mathrm{~mol} \%$ methanol in water.

The change in interface concentrations of $\mathrm{CO}_{2}$ as function of distance from the liquid side $(z=0)$ of the interface to hydrate side $(z=12)$ has been sampled using molecular dynamics simulations $[36,37]$ and fitted to a mathematical model for the profile as given by Equation (30) below:

$$
C(R)=\sum_{i=1}^{7} a_{i}\left[\arctan \left(0.6\left(\frac{z}{12}\right)\left(\frac{\pi}{2}\right)\right)\right]^{(i-1)}
$$

$z \in(0,12)$ with coefficient is Table 4 below.

Table 4. Coefficients for the fitted model of interface concentrations of $\mathrm{CO}_{2}$ from Equation (30).

\begin{tabular}{lc}
\hline \multicolumn{2}{c}{ Coefficients } \\
\hline$a_{1}$ & $3.649712 \times 10^{-4}$ \\
$a_{2}$ & $9.895427 \times 10^{-4}$ \\
$a_{3}$ & $1.091582 \times 10^{-2}$ \\
$a_{4}$ & $-1.112258 \times 10^{-1}$ \\
$a_{5}$ & $4.381832 \times 10^{-1}$ \\
$a_{6}$ & $-6.201765 \times 10^{-1}$ \\
$a_{7}$ & $2.896391 \times 10^{-1}$ \\
\hline
\end{tabular}


Fick's law for the mass transport part related to $J_{0}$ in Equation (23) can be expressed as:

$$
\frac{\partial C(z)}{\partial t}=-D_{\mathrm{CO}_{2}} \frac{\partial^{2} C(z)}{\partial z^{2}}
$$

where $C$ is concentration of $\mathrm{CO}_{2}, t$ is time, and $\mathrm{D}_{\mathrm{CO}_{2}}$ is the diffusivity of $\mathrm{CO}_{2}$ through the interface. An empirical and simple interpolation of diffusivities from liquid side to hydrate side is utilized just to illustrate the order of magnitude of nucleation times:

$$
-\log _{10}\left[\frac{D(R)_{j}}{D_{\text {liquid }, j}}\right]=\sum_{i=1}^{9} a_{i}\left(a \tan \left[\left(0.5 R \frac{\pi}{2}\right) / 12\right]\right)^{i-1}
$$

where $j=\mathrm{CO}_{2}$ or $\mathrm{CH}_{4}$.

This equation is an interpolation of some sampled molecular dynamics (MD) data from a hydrate block during dissociation. The samplings are not rigorous enough to serve as any real theoretical result. Diffusivities across an interface between liquid water and hydrate is complex and hard to calculate using MD. Equation (28) is therefore to be considered as empirical but with some qualified guessing based on molecular dynamics observations. Work is in progress on the development of other methods to estimate these diffusivities. We consider it as good enough for illustrating the order of magnitude of nucleation times. $\mathrm{R}$ is the distance from the liquid side of the interface. $D_{\text {liquid, }}$ is the diffusivity of the guest molecule $\left(\mathrm{CO}_{2}\right.$ or $\left.\mathrm{CH}_{4}\right)$ in the liquid outside the liquid side interface boundary. Even though $\mathrm{CO}_{2}$ is the focus of this work, $\mathrm{CH}_{4}$ is also listed since we did not find substantial differences in the water structure in the interface between hydrate of these two types of guest molecules. The parameters in Equation (28) are given in Table 5 below.

$$
t(R)-t(o)=\int_{C(R=0)}^{C(R=12)} \frac{\partial C(z)}{\left[-D_{C O_{2}} \frac{\partial^{2} C(z)}{\partial z^{2}}\right]}
$$

Table 5. Parameters for Equation (29).

\begin{tabular}{cccccc}
\hline $\boldsymbol{i}$ & Parameter & $\boldsymbol{i}$ & Parameter & $\boldsymbol{i}$ & Parameter \\
\hline 1 & 0.979242 & 4 & 171.673 & 7 & -9649.96 \\
2 & 15.5427 & 5 & 6.76975 & 8 & 14779.7 \\
3 & -88.5112 & 6 & 1939.55 & 9 & -7496.15 \\
\hline
\end{tabular}

Diffusivities of $\mathrm{CO}_{2}$ through hydrate vary between different sources in the open literature. All values are based on modelling, mainly using Monte Carlo approaches. It is beyond the scope of this work to screen all available studies and corresponding reported values. Reported values vary between $10^{-15} \mathrm{~m}^{2} / \mathrm{s}$ to $10^{-17} \mathrm{~m}^{2} / \mathrm{s}$. We simply choose $10^{-15} \mathrm{~m}^{2} / \mathrm{s}$ for $\mathrm{D}_{\mathrm{H}}$ and five conservative values for the liquid side of the interface; $10^{-9} \mathrm{~m}^{2} / \mathrm{s}, 10^{-10} \mathrm{~m}^{2} / \mathrm{s}, 10^{-11} \mathrm{~m}^{2} / \mathrm{s}, 10^{-12} \mathrm{~m}^{2} / \mathrm{s}$, and $10^{-13} \mathrm{~m}^{2} / \mathrm{s} \mathrm{just} \mathrm{to}$ illustrate a fairly conservative choice of mass transport characteristics across the interface. The lowest of these values for liquid side diffusivity coefficient gives a transport time for $\mathrm{CO}_{2}$ across the interface of $51 \mathrm{~ns}$, while the second smallest diffusivity coefficient results in a transport time of $5.1 \mathrm{~ns}$. Based on the structure and density of the $\mathrm{CO}_{2}$ on the liquid side of the profile in Figure $8 \mathrm{~b}$, these small diffusivities are unrealistically small and a liquid side diffusivity of $10^{-9} \mathrm{~m}^{2} / \mathrm{s}$ is used to calculate nucleation associated with critical nuclei sizes in Figure 7 . Results for pure water and three different concentrations of methanol in water are given in Figure 9. 


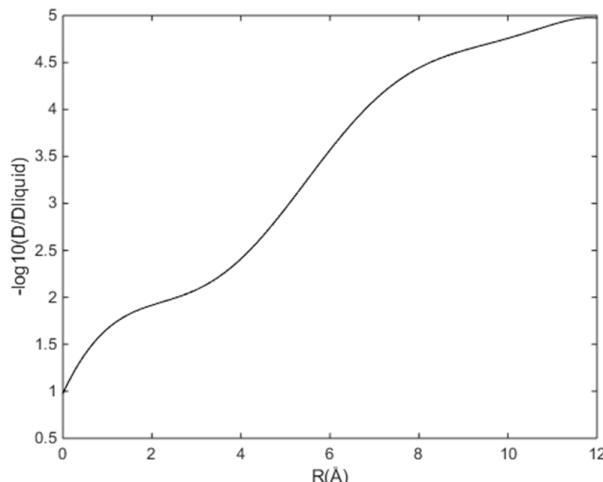

(a)

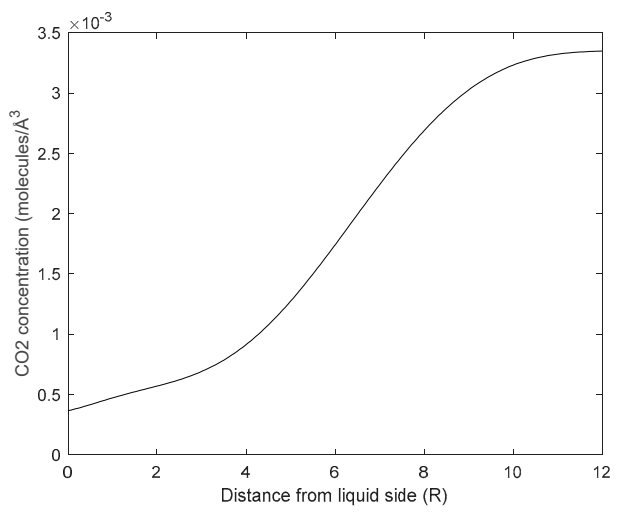

(b)

Figure 8. (a) Relative diffusivities for $\mathrm{CO}_{2}$ across the interface between water and the hydrate. $D$ is the interface diffusivity and $D_{\text {liquid }}$ is the diffusivity at the liquid side of the interface. (b) The concentration profile for $\mathrm{CO}_{2}$ as a function of distance from the liquid side of the interface.

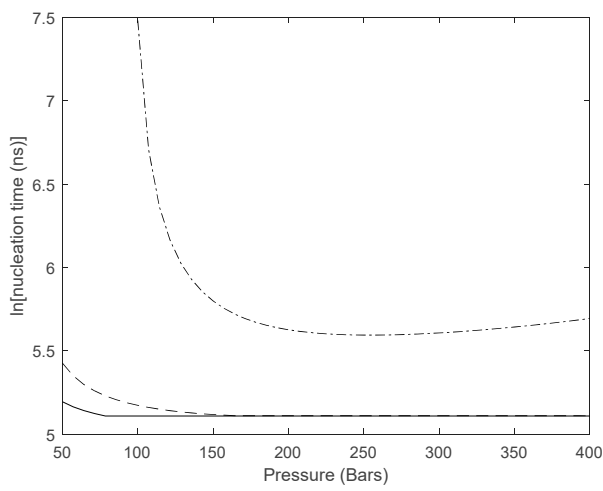

(a)

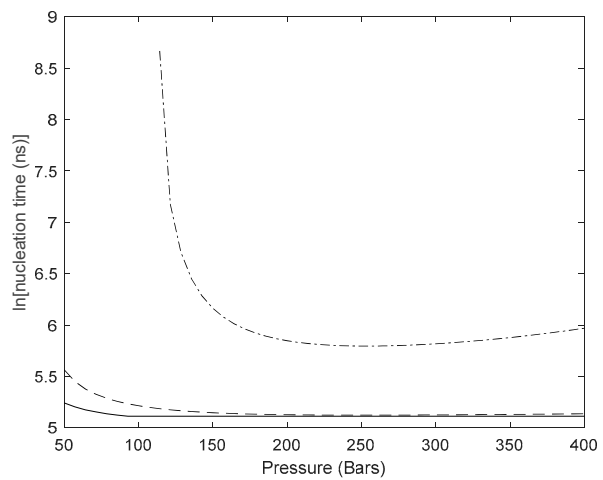

(c)

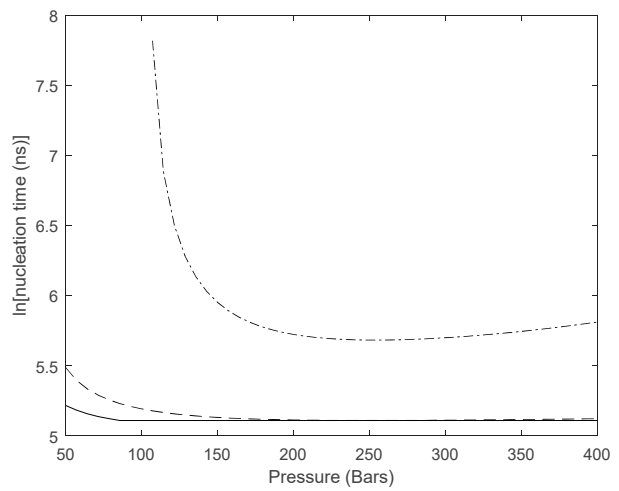

(b)

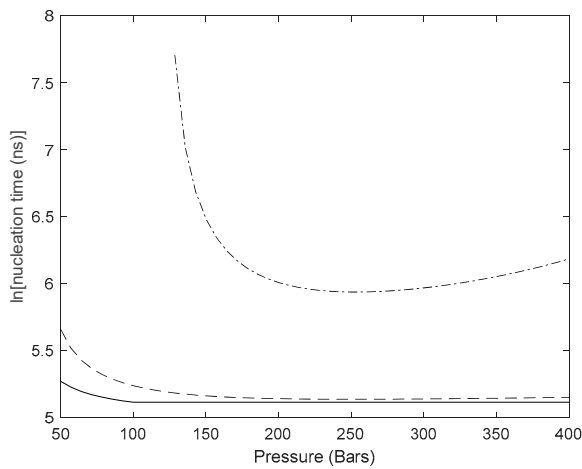

(d)

Figure 9. (a) Calculated nucleation times in nanoseconds using the concentration profiles as mathematically fitted using Equation (26) in Equation (27), together with Equation (28), for changes in diffusivity across the liquid water/hydrate interface. The applied diffusivity coefficient on the liquid side is $10^{-9} \mathrm{~m}^{2}$. The three different temperatures are $273.16 \mathrm{~K}$ (solid), $278.16 \mathrm{~K}$ (dash), and $283.16 \mathrm{~K}$ (dash-dot). (b) Same as (a) but now for $1 \mathrm{~mol} \%$ methanol in water. (c) Same as (a) but now for $2 \mathrm{~mol} \%$ methanol in water. (d) Same as (a) but for $3 \mathrm{~mol} \%$ methanol in water.

As mentioned, the interpolation in Equation (28) is empirical, but any type of model that contains some very slow diffusivity rates close to a hydrate (in accordance with the structure development of water) would still result in nanoscale nucleation times. The calculations behind the plots in Figure 9 are very conservative because of the very small value for the liquid-side diffusivity coefficient applied in Equation (28). Nucleation times may therefore very well be substantially faster than the curves indicate. 
The difference between $273.16 \mathrm{~K}$ and $278.16 \mathrm{~K}$ is not very significant, with asymptotic values for $166 \mathrm{~ns}$ and $172 \mathrm{~ns}$, respectively, for 400 bars pressure, while the corresponding value is $485 \mathrm{~ns}$ for $283.16 \mathrm{~K}$.

When nucleation times of several hours are reported, it is normally the first visible (human eye or microscope) hydrate. The development of this hydrate will be substantially delayed by slow transport through the hydrate film. We have also seen this when we utilized magnetic resonance imaging (MRI) [38] to monitor the development of $\mathrm{CH}_{4}$ hydrate formation in a compartment of plastic walls. The onset of massive growth that results in visible hydrate is given in terms of induction times. Several mechanisms are involved in the development towards induction time. The rearrangement of hydrates in lack of new hydrate building blocks, capillary transport towards solid walls, and heat release during formation of new hydrate are some of the factors.

Some estimates of hydrate film growth kinetics using a constant diffusivity coefficient though the hydrate film is given as Equation (33), and two liquid side coefficients to convert Equation (33) into a single constant value is shown in Figure 10 below. The resolution of the MRI experiment [38] is roughly 300 micron, and for the methane hydrate onset of massive growth, as could be seen in the MRI signal, the induction time was $100 \mathrm{~h}$.

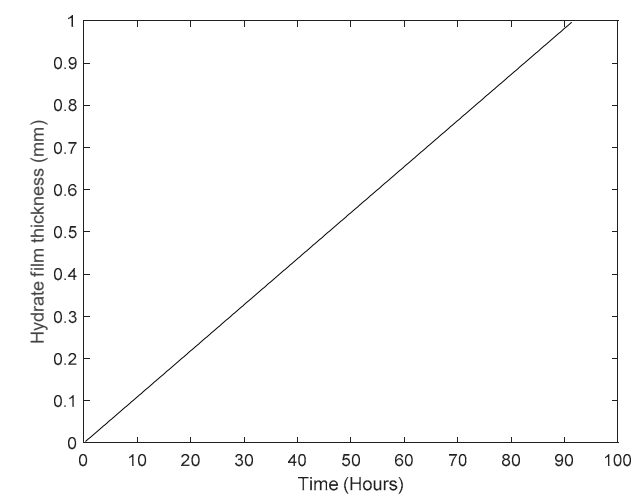

(a)

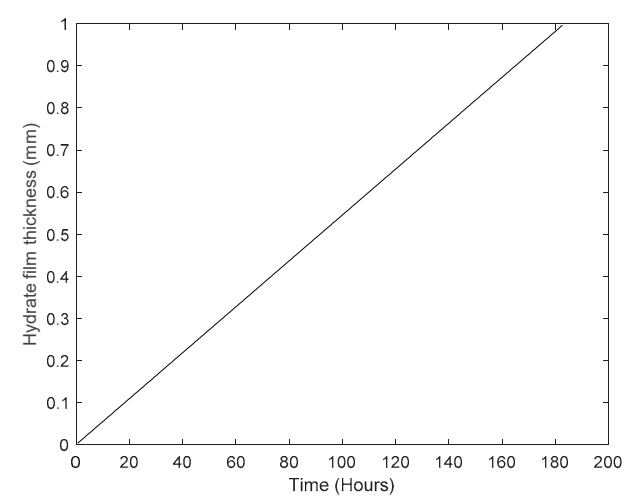

(b)

Figure 10. Time for growing $1 \mathrm{~mm}$ of $\mathrm{CO}_{2}$ hydrate with a constant diffusivity coefficient through the hydrate, as given in Equation (33), and two different choices for liquid diffusivity coefficients in Equation (33). Liquid diffusivity coefficient in equation equal to (a) $10^{-7} \mathrm{~m}^{2} / \mathrm{s}$, and (b) $5 \times 10^{-8} \mathrm{~m}^{2} / \mathrm{s}$.

\section{Residual Thermodynamic Modeling of Hydrate Formation from Water and Dissolved Hydrate Former in Water}

$$
\Delta G^{\left(H_{2}\right)}=\left[\begin{array}{c}
x_{H_{2} O}^{H}\left(\mu_{H_{2} O}^{H}\left(T, P, \vec{x}^{H}\right)-\mu_{H_{2} O}^{\text {water }}(T, P, \vec{x})\right) \\
+\sum_{j} x_{j}^{H}\left(\mu_{j}^{H}\left(T, P, \vec{x}^{H}\right)-\mu_{j}^{\text {water }}(T, P, \vec{x})\right)
\end{array}\right]
$$

where the superscript $\mathrm{H}_{2}$ now refers to homogeneous hydrate formation from liquid water and dissolved hydrate former in water, in accordance with a similar notation in Kvamme et al. [11]. The chemical potential for dissolved methane in water can then [11] be formulated as:

$$
\mu_{C H_{4}}^{\text {water }}(T, P, \vec{x})=\mu_{C H_{4}}^{\infty, \text { Residual }}(T, P, \vec{x})+\mu_{C H_{4}}^{\text {ideal gas }}(T, P, \vec{x})+R T \ln \left[x_{C H_{4}} \gamma_{C H_{4}}^{\infty}(T, P, \vec{x})\right]
$$

with

$$
\mu_{C H_{4}}^{\infty, \text { Residual }}=3.665+\frac{40.667}{T_{R}}-\frac{48.860}{T_{R}^{2}}
$$

where $T_{R}$ is temperature divided by the critical temperature for methane. The maximum temperature used in the fitting is $325 \mathrm{~K}$. Ideal gas as a function of temperature and density is trivial to consistently calculate using the TIP4P model moments in inertia for the rotational contribution [29]. 
The activity coefficient for methane in water, based on the asymmetric excess convention (activity coefficient for $\mathrm{CH}_{4}$ in water unity as mole-fraction $\mathrm{CH}_{4}$ goes to zero) has been fitted to the following function:

$$
\ln \gamma_{C H_{4}}^{\infty}(T, P, \vec{x})=\sum_{i=1,2}^{39}\left[a_{0}(i)+\frac{a_{1}(i+1)}{T_{R}}\right]\left(x_{C H_{4}}\right)^{\left[0.05+\frac{i-1}{40}\right]}
$$

where $T_{R}$ is the reduced temperature and defined as actual $T$ in Kelvin divided by the critical temperature for methane (190.6 K). The lower summation 1,2 indicates starting from 1 and counting in steps of 2. Parameters are given in Kvamme et al. [11] (Table 3 in that paper).

For $\mathrm{CO}_{2}$, a slightly different approach is utilized. The density of $\mathrm{CO}_{2}$ as dissolved in water will correspond to the partial molar volume of $\mathrm{CO}_{2}$ at infinite dilution. The infinite dilution ideal gas chemical potential is not very sensitive to pressure, so the following approximation to only temperature dependency is considered as adequate:

$$
\mu_{\mathrm{CO}_{2}}^{\infty, \text { idealgas }}=-130.006+\frac{163.818}{T_{0, R}}-\frac{64.898}{T_{0, R}^{2}}
$$

where $T_{0, R}$ is $273.15 \mathrm{~K}$ divided by the actual temperature. Equation (34) does not apply to temperatures above $303 \mathrm{~K}$ due to the limited range of temperatures for which infinite partial molar volumes are used, and for temperatures above $273.15 \mathrm{~K}$.

The fugacity coefficient for $\mathrm{CO}_{2}$ in water is fitted using the following function:

$$
\ln \phi_{\mathrm{CO}_{2}}^{\text {water }}(T, P, \vec{x})=\sum_{i=1,2}^{39}\left[a_{0}(i)+\frac{a_{1}(i+1)}{T_{R}}\right]\left(x_{\mathrm{CO}_{2}}\right)^{\left[0.05+\frac{i-1}{40}\right]}
$$

where $T_{R}$ is reduced temperature and defined as actual $T$ in Kelvin divided by critical temperature for $\mathrm{CO}_{2}(304.35 \mathrm{~K})$. The lower summation 1, 2 indicates starting from 1 and counting in steps of 2. Parameters are given in Table 6 below. The vector sign on mole-fraction $x$ denote the vector of mole-fractions $i$.

Table 6. Parameters for Equation (28).

\begin{tabular}{cccccc}
\hline $\boldsymbol{i}$ & $\boldsymbol{a}_{\mathbf{0}}$ & $\boldsymbol{a}_{\mathbf{1}}$ & $\boldsymbol{i}$ & $\boldsymbol{a}_{\mathbf{0}}$ & $\boldsymbol{a}_{\mathbf{1}}$ \\
\hline 1 & -139.137483 & -138.899061 & 21 & 79.373137 & 85.956670 \\
3 & -76.549658 & -72.397006 & 23 & 75.429910 & 81.519167 \\
5 & -20.868725 & -14.715982 & 25 & 70.680932 & 76.270320 \\
7 & 18.030987 & 24.548835 & 27 & 65.490785 & 70.551406 \\
9 & 44.210433 & 52.904238 & 29 & 60.126698 & 64.683147 \\
11 & 63.353037 & 71.596515 & 31 & 54.782421 & 58.865478 \\
13 & 74.713278 & 82.605791 & 33 & 49.592998 & 53.235844 \\
15 & 80.411175 & 88.536302 & 35 & 44.500001 & 47.728622 \\
17 & 82.710575 & 90.262518 & 37 & 39.869990 & 42.730831 \\
19 & 82.017332 & 89.094887 & 39 & 35.597488 & 38.125674 \\
\hline
\end{tabular}

The chemical potential for $\mathrm{CO}_{2}$ that applies to Equations (4) and (8) for an equilibrium case is then given as:

$$
\mu_{\mathrm{CO}_{2}}(T, P, \vec{y})=\mu_{\mathrm{CO}_{2}}^{\infty, \text { idealgas }}(T, P, \vec{y})+R T \ln \left[x_{\mathrm{CO}_{2}} \phi_{\mathrm{CO}_{2}}(T, P, \vec{y})\right]
$$

Since the chemical potential of $\mathrm{CO}_{2}$ is not necessarily the same for dissolved $\mathrm{CO}_{2}$ in water and $\mathrm{CO}_{2}$ in gas (or liquid) in a non-equilibrium situation, then hydrate formed according to Equation (2) will be different from the first hydrate and accordingly denoted $\mathrm{H}_{2}$. The composition of this hydrate will be different as seen from the corresponding compositions, which follows from Equations (4)-(8). 
For homogeneous hydrate formation from liquid water and a dissolved hydrate former, the number of degrees of freedom (Gibbs phase rule) is 2. Each specific set of temperature and pressure will have a maximum dissolved content of hydrate former according a Henry's law type of calculation [11]. These values are trivially found through iterative solutions of chemical potential for $\mathrm{CO}_{2}$ in water solution being equal to $\mathrm{CO}_{2}$ in a separate phase. In this work, we have used the SRK [30] equation of state for calculating gas (or liquid) $\mathrm{CO}_{2}$ fugacity coefficients.

For the same set of temperature and pressure, there is a unique minimum content of hydrate former in the liquid water that is needed to keep the hydrate stable. These limits are found from equal chemical potentials for water in liquid and hydrate when chemical potential for $\mathrm{CO}_{2}$ from Equation (36) is used in Equation (4), as given by Equation (37) below. Examples for $\mathrm{CH}_{4}$ are given in Figure 11 below for $\mathrm{CH}_{4}$ for a larger range of temperatures and pressures than those reported by Kvamme et al. [11]. Similar results for $\mathrm{CO}_{2}$ are given in Figure 12.

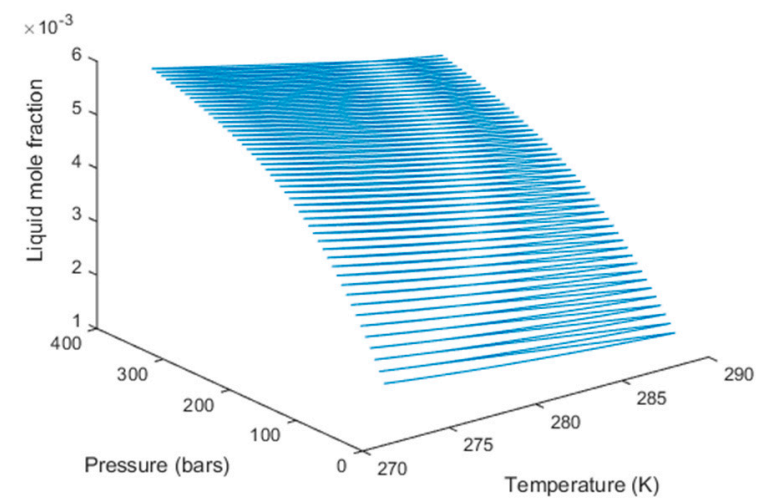

(a)

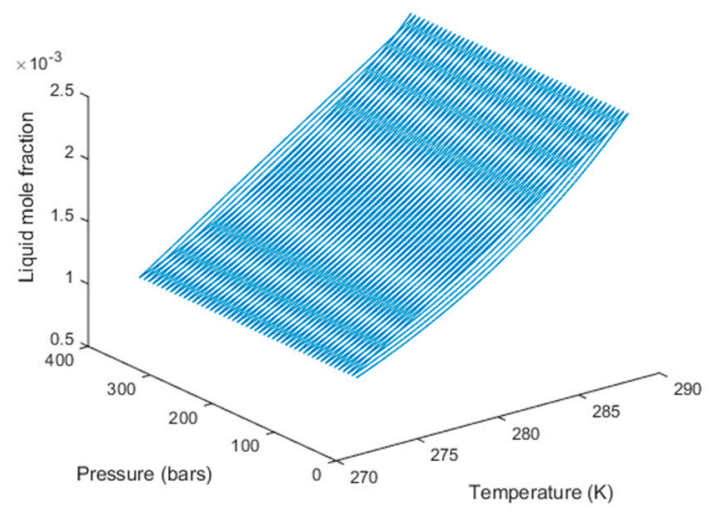

(b)

Figure 11. (a) Calculated solubility of $\mathrm{CH}_{4}$ in water. (b) Calculated minimum limits of mole-fraction $\mathrm{CH}_{4}$ in water to keep the hydrate stable.

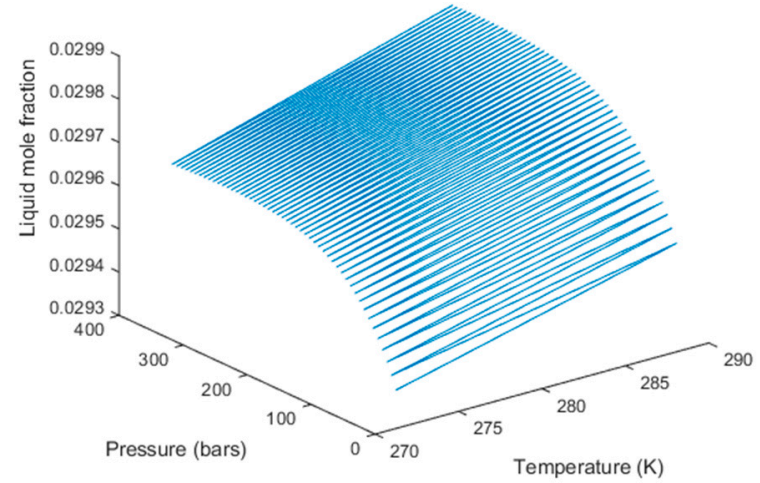

(a)

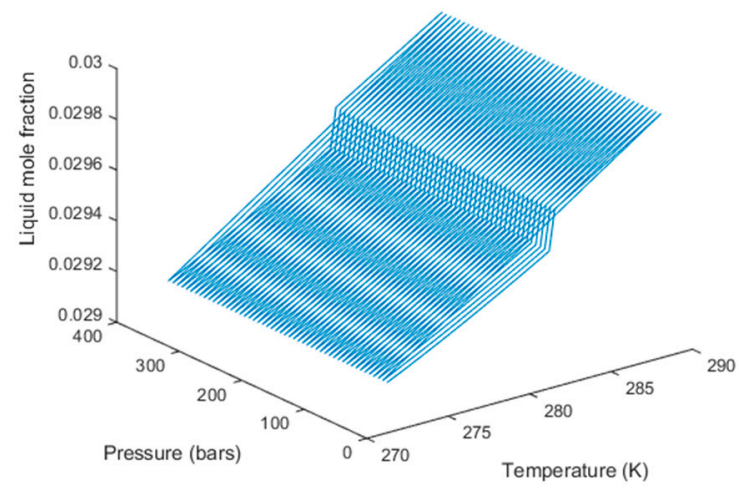

(b)

Figure 12. (a) Calculated solubility of $\mathrm{CO}_{2}$ in water. (b) Calculated minimum limits of mole-fraction $\mathrm{CO}_{2}$ in water to keep the hydrate stable.

Note the strange frame that is drawn between the corners of Figures $11 b$ and $12 b$, which is an artificial bug in the graphical software. This is of course not a physical part of the calculated data, and must accordingly be neglected in the reading of the curves. In Figure $12 b$, there is as such a fairly steep change in liquid mole-fraction for the lower limit of hydrate stability. For methane, which does not have a sharp density increase in the same range, the contours in Figure $11 \mathrm{~b}$ are slightly concave, and again, the outer strange "side-walls" are not physical. 
The only change in Equation (3) for this case is in the cavity partition functions such that Equation (4), now with more specific notations, can be written at equilibrium as:

$$
h_{k i}=e^{\beta\left[\mu_{k i}^{\text {water }}(T, P, \bar{x})-\Delta g_{k i}(T)\right]}
$$

where the chemical potentials are either from Equation (35) for $\mathrm{CO}_{2}$. For the case of equilibrium, it is assumed that chemical potential for the guest molecule has same chemical potential in both cavities. Outside of equilibrium, Equation (39) applies and the Taylor expansion will also imply that the chemical potentials of guest molecules in the two types of cavities are not necessarily the same.

A second set of changes, relative to the case of separate phases for water and hydrate former, lies in the enthalpy for the hydrate former that enters in the changes associated with the phase transition:

$$
H_{\mathrm{CO}_{2}}^{R}=-R T^{2}\left[\frac{\partial \ln \phi_{\mathrm{CO}}^{\text {water }}}{\partial T}\right]_{P, y_{j \neq \mathrm{CO} 2}}
$$

and:

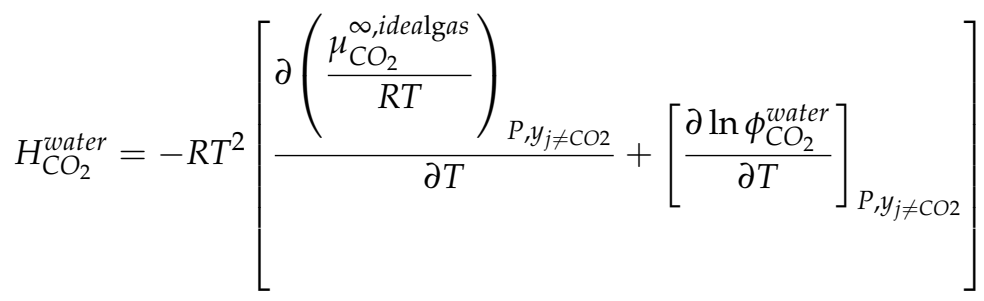

An example for nucleation of hydrate from solution is given in Figure 13 below. As expected, the critical nuclei radius decreases substantially when the concentration of $\mathrm{CO}_{2}$ in the water gets closer to the solubility curve. Furthermore, very close to the hydrate stability limit concentrations, the critical radius approaches impossible sizes. The same is reflected in the corresponding nucleation times.
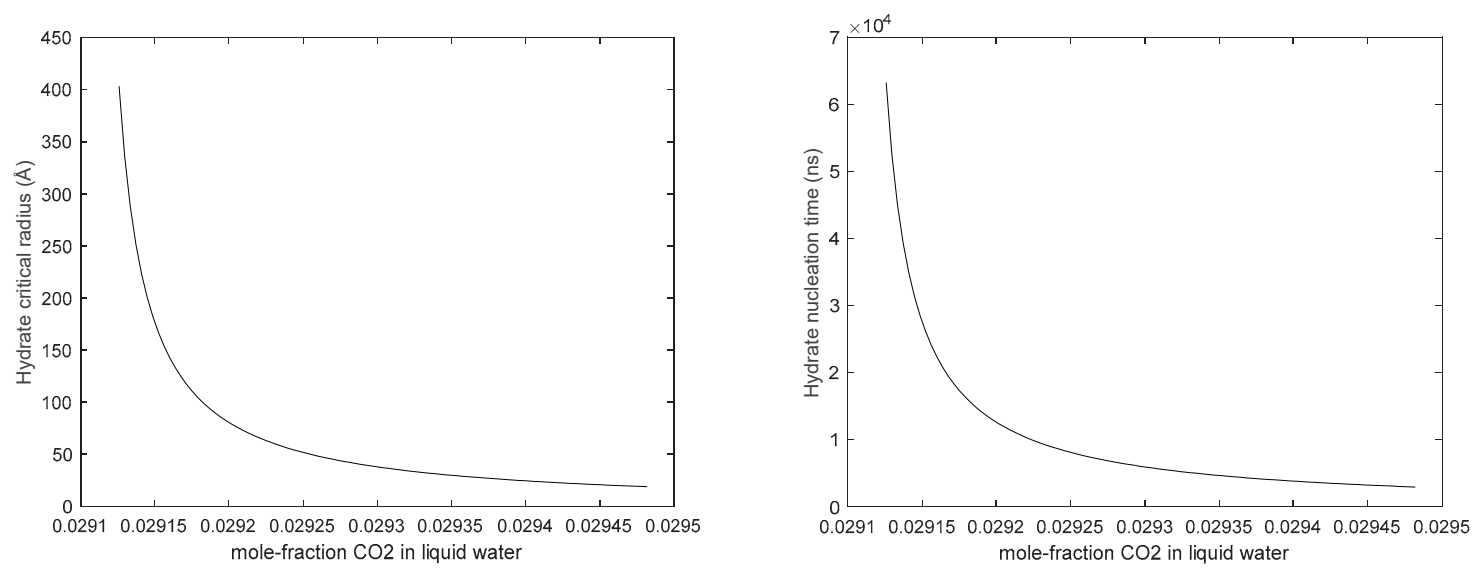

Figure 13. (a) Critical nuclei size for $\mathrm{CO}_{2}$ hydrate forming from dissolved $\mathrm{CO}_{2}$ in water as a function of $\mathrm{CO}_{2}$ concentration in water at $273.16 \mathrm{~K}$ and 100 bar. (b) Calculated nucleation times as a function of $\mathrm{CO}_{2}$ concentration in water.

The heat of formation from liquid solution is smaller than the values for formation from gas and liquid since changes in enthalpy for the guest molecules is smaller. Some examples are plotted in Figure $14 \mathrm{~b}$ below. Practically, these are interesting since the most likely hydrate formation from solution is towards the existing hydrate film formed from water and a separate $\mathrm{CO}_{2}$ phase. The released heat will then distribute between dissipation into the water below or heating and potentially dissociating the hydrate locally. The dash-dot curves for $283.16 \mathrm{~K}$ in Figure 14a,b may be hard to see from the way the graphical software presented them. In Figure 14a, this is the short curve highest up, and in Figure 14b, it is the short curve on the bottom. 


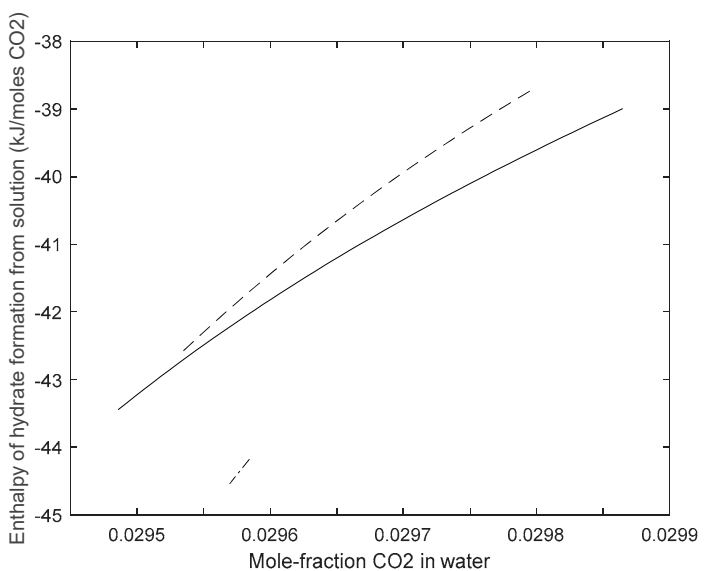

(a)

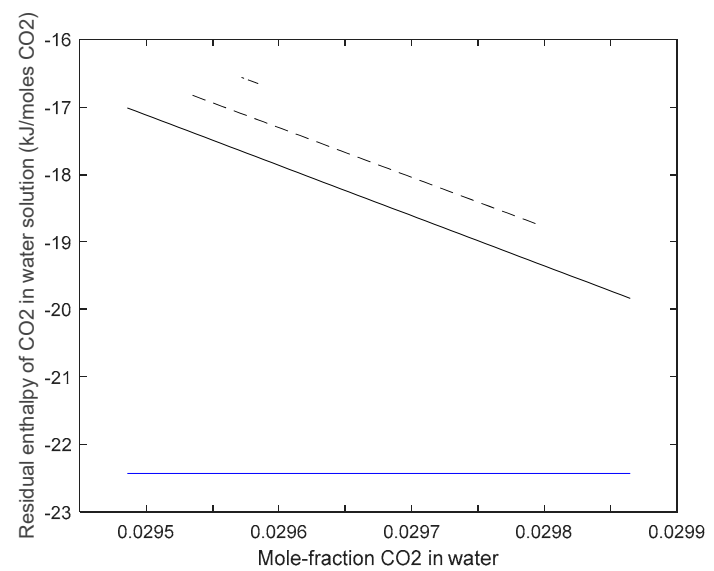

(b)

Figure 14. (a) Residual enthalpy for $\mathrm{CO}_{2}$ in liquid water at 100 bar and three temperatures: $273.16 \mathrm{~K}$ (solid black), $278.16 \mathrm{~K}$ (dash), and $283.16 \mathrm{~K}$ (dash-dot). The solid blue line is the residual enthalpy for $\mathrm{CO}_{2}$ in a large cavity of structure I and not significantly sensitive to temperature for this limited temperature range. (b) Enthalpies of formation of $\mathrm{CO}_{2}$ hydrate from liquid solution in water at 100 bar and three different temperatures: $273.16 \mathrm{~K}$ (solid), $278.16 \mathrm{~K}$ (dash), and $283.16 \mathrm{~K}$ (dash-dot).

\section{Discussion}

Two very common misunderstandings are related to Figure 4 . The first of these is related to the shape of the equilibrium curve. It is not our intention to criticize experimental groups here but as discussed by Kvamme and Aromada [20], the transition over to higher density for $\mathrm{CO}_{2}$ also results in a sharp transition of equilibrium pressures. This transition is frequently smoothed out when experimental data are published. Another misunderstanding is that the pressure and temperature projection of the stability region is discussed as $\mathrm{CH}_{4}$ being more stable than $\mathrm{CH}_{4}$ hydrate after this region of change in density for $\mathrm{CO}_{2}$ because the equilibrium pressures for $\mathrm{CH}_{4}$ then become lower, as seen from Figure 4a. Stability is a multidimensional function of all independent thermodynamic variables like pressure, temperature, and concentrations of all components in all phases. As such, the temperature and pressure projection only tells part of the story. Figure 7 tells other parts of the story. Furthermore, the free energy of $\mathrm{CO}_{2}$ hydrate is lower than the free energy of $\mathrm{CH}_{4}$ hydrate for all pressures and temperatures. These are comparable free energies since all components and all phases are based on residual thermodynamic descriptions, and as such, are consistent.

The concept of using $\mathrm{CO}_{2}$ for the combined production of $\mathrm{CH}_{4}$ and long-term safe storage of $\mathrm{CO}_{2}$ as hydrate has been misunderstood in many experimental reports. We have used very conservative transport properties in kinetic modeling of $\mathrm{CO}_{2}$ hydrate formation from separate $\mathrm{CO}_{2}$ phase and from solution. Furthermore, even with low diffusion rates for the supply of mass to nucleation and growth, the nucleation times hardly exceed some few hundred nanoseconds. Transport through these hydrate films, in order to sustain further growth, is extremely slow, and even to grow 1 millimeter may take several hours. Even though these estimates are oversimplified, there is no doubt that $\mathrm{CO}_{2}$ diffusivity coefficients through hydrate in the order of $10^{-15} \mathrm{~m}^{2} / \mathrm{s}$ to $10^{-17} \mathrm{~m}^{2} / \mathrm{s}$ creates substantial delays in the growth up to visible hydrate film range. Addition of small amounts of surface-active components can solve these problems as discussed by Kvamme et al. [11] in a recent paper. 


\section{Conclusions}

Many experimental groups around the world have been conducting experiments on the exchange on $\mathrm{CH}_{4}$ hydrate with $\mathrm{CO}_{2}$. Frequent conclusions end up with the process being far too slow. Some end up adding nitrogen or other gases, which often leads to even slower conversion because the thermodynamic driving forces for the critical parts of the mechanism is reduced. There are two verified mechanisms for the conversion but one of them, the solid-state conversion mechanism, has only been proven in the ice region far below $0{ }^{\circ} \mathrm{C}$. The other mechanism, which has been proven by state-of-the-art theoretical approaches involves the creation of a new hydrate from the injected $\mathrm{CO}_{2}$. In this work, we have demonstrated a new approach for calculating enthalpies of hydrate formation and have shown that the released heat of formation of $\mathrm{CO}_{2}$ hydrate may be $10 \mathrm{~kJ} / \mathrm{mole}$ of hydrate former higher than similar number for $\mathrm{CH}_{4}$ hydrate. We have also demonstrated that the free energy of $\mathrm{CO}_{2}$ hydrate is in the order of $2 \mathrm{~kJ} /$ mole hydrate lower for $\mathrm{CO}_{2}$ hydrate as compared to $\mathrm{CH}_{4}$ hydrate. This latter piece of information is important since the formation of a new $\mathrm{CO}_{2}$ hydrate will lead to an increase in ion activity for the remaining liquid water. The lower free energy for the $\mathrm{CO}_{2}$ hydrate implies that $\mathrm{CH}_{4}$ hydrate is more affected by the increased ion activity in terms of destabilization. The problem with the $\mathrm{CO}_{2}$ injection method is that hydrate films form very fast. In this work, we have utilized classical nucleation theory (CNT) with very slow transport characteristics so as to be conservative. Despite this, it is hard to get nucleation times that exceed some few hundred nanoseconds. Furthermore, transport of mass through these hydrates is extremely slow. There are many sources of data that publish diffusivities for $\mathrm{CH}_{4}$ or $\mathrm{CO}_{2}$ but reported values vary a lot between $10^{-15} \mathrm{~m}^{2} / \mathrm{s}$ and $10^{-17} \mathrm{~m}^{2} / \mathrm{s}$. With values like this and oversimplified estimates, it is easy to verify that even creating a $1 \mathrm{~mm}$ hydrate film of $\mathrm{CO}_{2}$ can take hundreds of hours. This is also in accordance with previous results from our group that reported visible (on a 300-micron resolution scale experiment) hydrate from $\mathrm{CH}_{4}$ and water after $100 \mathrm{~h}$. Based on our earlier results on adding small amounts of alcohols or surfactants, we proposed the addition of these types of chemicals rather than addition of nitrogen or other gases that makes it less likely to generate new hydrate. The key lesson here is to keep the $\mathrm{CO}_{2}$ / water interface free of hydrate films.

Funding: This research received no external funding.

Conflicts of Interest: The author declares no conflict of interest.

\section{References}

1. Dallimore, S.R.; Uchida, T.; Collett, T.S. (Eds.) Scientific Results from JAPEX/JNOC/GSC Mallik 2L-38 Gas Hydrate Research Well, Mackenzie Delta, Northwest Territories, Canada; Bulletin 544; Geological Survey of Canada: Ottawa, ON, Canada, 1999.

2. Hancock, S.H.; Collett, T.S.; Dallimore, S.R.; Satoh, T.; Inoue, T.; Huenges, E.; Henninges, J.; Weatherill, B. Overview of Thermal-Stimulation Production-Test Results for the JAPEX/JNOC/GSC et al. Mallik 5 L38 Gas Hydrate Production Research Well; Bulletin 585; Geological Survey of Canada: Ottawa, ON, Canada, 2005.

3. Konno, Y. Recent Status of Methane Hydrate R\&D Program in Japan. Oral Presentation at the Nanotechnology and Nano-Geoscience in Oil and Gas Industry, Kyoto, Japan, 4-8 March 2014; National Institute of Advanced Industrial Science and Technology (AIST): Tokyo, Japan, 2014.

4. Tenma, N. Recent Status of Methane Hydrate R\&D Program in Japan. In Proceedings of the 11th International Methane Hydrate Research and Development, Corpus Christie, TX, USA, 5-8 December 2017.

5. Lee, H.; Seo, Y.; Seo, Y.-T.; Moudrakovski, I.L.; Ripmeester, J.A. Recovering Methane from Solid Methane Hydrate with Carbon Dioxide. Angew. Chem. Int. Ed. 2003, 115, 5202-5205. [CrossRef]

6. Falenty, A.; Genov, G.; Hansen, T.C.; Kuhs, W.F.; Salamatin, A.N. Kinetics of $\mathrm{CO}_{2}$-Hydrate Formation from Water Frost at Low Temperatures: Experimental Results and Theoretical Model. J. Phys. Chem. C 2010, 115, 4022-4032. [CrossRef]

7. Baig, K. Nano to Micro Scale Modeling of Hydrate Phase Transition Kinetics. Ph.D. Thesis, University of Bergen, Bergen, Norway, 2017. 
8. Baig, K.; Kvamme, B.; Kuznetsova, T.; Bauman, J. The impact of water/hydrate film thickness on the kinetic rate of mixed hydrate formation during $\mathrm{CO}_{2}$ injection into $\mathrm{CH}_{4}$ hydrate. AIChE J. 2015, 61, 3944-3957. [CrossRef]

9. Schoderbek, D.; Farrell, H.; Hester, K.; Howard, J.; Raterman, K.; Silpngarmlert, S.; Lloyd Martin, K.; Smith, B.; Klein, P. ConocoPhillips Gas Hydrate Production Test Final Technical Report October 1, 2008-June 30, 2013; DOE Award No.: DE-NT0006553; ConocoPhillips Company for United States Department of Energy National Energy Technology Laboratory: Houston, TX, USA, 20 July 2013.

10. Kvamme, B. Thermodynamic limitations of the $\mathrm{CO}_{2} / \mathrm{N}_{2}$ mixture injected into $\mathrm{CH}_{4}$ hydrate in the Ignik Sikumi field trial. J. Chem. Eng. Data 2016, 61, 1280-1295. [CrossRef]

11. Kvamme, B.; Selvåg, J.; Aromada, S.A.; Saeidi, N.; Kuznetsova, T. Methanol as hydrate inhibitor and hydrate activator. Phys. Chem. Chem. Phys. 2018, 20, 21968-21987. [CrossRef]

12. Austvik, T.; Hustvedt, E.; Gjertsen, L.H. Formation and removal of hydrate plugs—Field trial at Tommeliten. In Proceedings of the 76 Annual Meeting of the Gas Processors Association (GPA), San Antonio, TX, USA, 10-12 March 1997; p. 249.

13. Bavoh, C.B.; Partoon, B.; Laland, B.; Keong, L.K. Methane hydrate liquid-vapour-equilibrium phase condition measurements in the presence of natural amino acids. J. Nat. Gas Sci. Eng. 2017, 37, 425-434. [CrossRef]

14. Tumba, K.; Reddy, P.; Naidoo, P.; Ramjugernath, D.; Eslamimanesh, A.; Mohammadi, A.H.; Richon, D. Phase equilibria of methane and carbon dioxide clathrate hydrates in the presence of aqueous solutions of tributylmethylphosphonium methylsulfate ionic liquid. J. Chem. Eng. Data 2011, 56, 3620-3629. [CrossRef]

15. Sabil, K.M.; Nashed, O.; Lal, B.; Ismail, B.; Japper-jaafar, A. Experimental investigation on the dissociation conditions of methane hydrate in the presence of imidazolium-based ionic liquids. Thermodyn. J. Chem. 2015, 84, 7-13. [CrossRef]

16. Svartas, T.M.; Fadnes, F.H. Methane hydrate equilibrium data for the methane-water-methanol system up to 500 bara. In Proceedings of the Second International Offshore and Polar Engineering Conference, San Francisco, CA, USA, 14-19 June 1992; pp. 614-619.

17. Ng, H.-J.; Robinson, D.B. Hydrate formation in systems containing methane, ethane, propane, carbon dioxide or hydrogen sulfide in the presence of methanol. Fluid Phase Equilibria 1985, 21, 145-155. [CrossRef]

18. Kvamme, B.; Aromada, S.A. Risk of hydrate formation during processing and transport of Troll gas from the North Sea. J. Chem. Eng. Data 2017, 62, 2163-2177. [CrossRef]

19. Kvamme, B.; Aromada, S.A.; Kuznetsova, T.; Berge Gjerstad, P.; Canonge, P.C.; Zarifi, M. Maximum tolerance for water content at various stages of a Natuna production. Heat Mass Transf. 2019, 55, 1059-1079. [CrossRef]

20. Kvamme, B.; Aromada, S.A. Alternative Routes to Hydrate Formation during Processing and Transport of Natural Gas with Significant Amount of $\mathrm{CO}_{2}$ : Sleipner Gas as a Case Study. J. Chem. Eng. Data 2018, 63, 832-844. [CrossRef]

21. Kvamme, B.; Sapate, A. Hydrate Risk Evaluation during Transport and Processing of Natural Gas Mixtures containing Ethane and Methane. Res. Rev. J. Chem. 2016, 5, 64-74.

22. Kvamme, B.; Nesse Knarvik, A.B.; Austrheim, M.; Zarifi, M. Impact of solid surfaces on hydrate formation during processing and transport of hydrocarbons. Int. J. Eng. Res. Dev. 2017, 13, 1-16.

23. Aromada, S.A.; Kvamme, B. Impacts of carbon dioxide and hydrogen sulphide on the risk of hydrate formation during pipeline transport of Natural gas. Front. Chem. Sci. Eng. 2018, in press.

24. Aromada, S.A.; Kvamme, B. New Approach for Evaluating the Risk of Hydrate formation During Transport of Hydrocarbon Hydrate formers of sI and sII. AIChE J. 2018, in press. [CrossRef]

25. Kvamme, B.; Kuznetsova, T.; Stensholt, S.; Sjøblom, S. Investigating chemical potential of water and H2S dissolved into $\mathrm{CO}_{2}$ using molecular dynamics simulations and Gibbs-Duhem relation. J. Chem. Eng. Data 2015, 60, 2906-2914. [CrossRef]

26. Kvamme, B. Feasibility of simultaneous $\mathrm{CO}_{2}$ storage and $\mathrm{CH}_{4}$ production from natural gas hydrate using mixtures of $\mathrm{CO}_{2}$ and $\mathrm{N}_{2}$. Can. J. Chem. 2015, 93, 897-905. [CrossRef]

27. Kuznetsova, T.; Jensen, B.; Kvamme, B.; Sjøblom, S. Water wetting surfaces as hydrate promotes during transport of carbon dioxide with impurities. Phys. Chem. Chem. Phys. 2015, 17, 12683-12697. [CrossRef]

28. Kvamme, B.; Kuznetsova, T.; Bauman, J.M.; Sjöblom, S.; Kulkarni, A.A. Hydrate Formation during Transport of Natural Gas Containing Water and Impurities. J. Chem. Eng. Data 2016, 61, 936-949. [CrossRef]

29. Kvamme, B.; Tanaka, H. Thermodynamic stability of hydrates for ethylene, ethane and carbon dioxide. J. Phys. Chem. 1995, 99, 7114-7119. [CrossRef] 
30. Soave, G. Equilibrium constants from a modified Redlich-Kwong equation of state. Chem. Eng. Sci. 1972, 27, 1197-1203. [CrossRef]

31. Kvamme, B.; Lund, A. The influence of gas-gas interactions on the langmuir-constants for some natural gas hydrates. Fluid Phase Equilibria 1993, 90, 15-44. [CrossRef]

32. Kvamme, B.; Førrisdahl, O.K. Polar guest-molecules in natural gas hydrates. Fluid Phase Equilibria 1993, 83, 427-435. [CrossRef]

33. Kvamme, B. Droplets of Dry Ice and Cold Liquid $\mathrm{CO}_{2}$ for Self-Transport of $\mathrm{CO}_{2}$ to Large Depths. Int. J. Offshore Polar Eng. 2003, 13, 139.

34. Kvamme, B. Kinetics of Hydrate Formation from Nucleation Theory. Int. J. Offshore Polar Eng. 2002, $12,256$.

35. Kvamme, B. Initiation and Growth of Hydrate. Ann. N. Y. Acad. Sci. 2000, 912, 496-501. [CrossRef]

36. Svandal, A.; Kuznetsova, T.; Kvamme, B. Thermodynamic properties and phase transitions in the $\mathrm{H}_{2} \mathrm{O} / \mathrm{CO}_{2} / \mathrm{CH}_{4}$ system. Fluid Phase Equilibria 2006, 246, 177-184. [CrossRef]

37. Svandal, A. Modeling Hydrate Phase Transitions Using Mean-Field Approaches. Ph.D. Thesis, University of Bergen, Bergen, Norway, 2006.

38. Kvamme, B.; Graue, A.; Buanes, T.; Kuznetsova, T.; Ersland, G. Storage of $\mathrm{CO}_{2}$ in natural gas hydrate reservoirs and the effect of hydrate as an extra sealing in cold aquifers. Int. J. Greenh. Gas Control 2007, 1, 236-246. [CrossRef]

(C) 2019 by the author. Licensee MDPI, Basel, Switzerland. This article is an open access article distributed under the terms and conditions of the Creative Commons Attribution (CC BY) license (http:// creativecommons.org/licenses/by/4.0/). 